\title{
Comparative study of larvae of Tenebrionoidea (Coleoptera: Cucujiformia)
}

\author{
RolF GEORg BEUTEL and Frank FRIEDRICH
}

\begin{abstract}
Institut für Spezielle Zoologie und Evolutionsbiologie, FSU Jena, 07743 Jena, Germany; e-mails: b5bero@rz.uni-jena.de,
\end{abstract} frank.friedrich@uni-jena.de

Key words. Tenebrionoidea, larvae, morphology, character evolution, phylogeny

\begin{abstract}
External and internal head structures and external structures of the thorax and abdomen of larval representatives of Melandryidae (Orchesia), Ulodidae (Meryx), Oedemeridae (Pseudolycus) and Pythidae (Pytho) are described. The obtained data were compared to characters of other tenebrionoid larvae and to larval characters of other representatives of Cucujiformia. Characters potentially relevant for phylogenetic reconstruction are listed and were analysed cladistically. The data set is characterised by a high degree of homoplasy and the resolution of the strict consensus trees of 2650 or 815 (second analysis) minimal length trees is low. The monophyly of Tenebrionoidea is supported by several larval autapomorphies, e.g. posteriorly diverging gula, anteriorly shifted posterior tentorial arms, asymmetric mandibles and the origin of several bundles of $\mathrm{M}$. tentoriopharyngalis from the well-developed gular ridges. Several features of the larval head are plesiomorphic compared to the cleroid-cucujoid lineage. The interrelationships of most tenebrionoid families not belonging to the pythid-salpingid and anthicid-scraptiid groups were not resolved. Synchroidae were placed as sister group of a clade comprising these two lineages and Prostomidae. A sistergroup relationship between Trictenotomidae and Pythidae seems to be well supported and the monophyly of the anthicid-scraptiid lineage was also confirmed. Another potential clade comprises Prostomidae, Mycteridae and Boridae, and possibly Pyrochroidae (s.str.) and Inopeplinae. The monophyly of Salpingidae (incl. Othniinae and Inopelinae) and Pyrochroidae (incl. Pedilinae) was not supported. Many features such as the shape of the head and body, sutures and ridges of the head capsule, the endocarina, the mandibles, the maxillary apex, and also characters of the terminal abdominal apex are highly variable, even within families. Especially the families Tetratomidae, Melandryidae, Colydiidae and Zopheridae show a high degree of variation in the larval stages. Several taxa appear isolated in terms of larval morphology within the families they are assigned to, e.g. Orchesia within Melandryidae, Sphindocis (Sphindocinae) within Ciidae, Calopus (Calopinae) within Oedemeridae and Penthe (Penthinae) within Tetratomidae. A broader spectrum of characters and a stepwise approach will be needed for a reliable clarification of the relationships within a very complex group like Tenebrionoidea.
\end{abstract}

\section{INTRODUCTION}

With approximately 30,000 described species and 30 currently recognised families (Lawrence \& Newton, 1995), Tenebrionoidea is a large and complex superfamily of cucujiform beetles. The composition of the group is largely agreed upon (Lawrence \& Newton, 1995). However, the monophyly is not well founded and the interrelationships of the families are largely unresolved despite of a considerable number of phylogenetic investigations (e.g. Crowson, 1966; Abdullah, 1973, 1974; Lawrence, 1977; Doyen \& Lawrence, 1979; Pollock, 1995; Pollock \& Lawrence, 1995). A large number of studies on tenebrionoid larvae have been published. However, most of them are not very detailed, and a thorough description of internal structures is only available for a single species, Tenebrio molitor (Jösting, 1942). Therefore, the main goal of this study is to improve the knowledge of the larval morphology of Tenebrionoidea. For the detailed descriptions, four larvae representing different families and morphological types were chosen: Orchesia micans (Panzer, 1794) (Melandryidae), Pseudolycus haemorrhoidalis (Fabricius, 1801) (Oedemeridae), Meryx sp. (Ulodidae) and Pytho niger Kirby, 1837 (Pythidae). The findings are compared to structural features of other tenebrionoid larvae, and a list of characters potentially useful for phylogenetic reconstruction and a character state matrix are presented (Table 1). The data for most families were taken from the literature (e.g., Lawrence, 1977, 1991; Lawrence \& Spilman, 1991; Pollock, 1995; Pollock \& Lawrence, 1995; Pollock et al., 2000; Selander, 1991; Young, 1991). A cladistic analysis was carried out even though it was apparent that the use of the larval characters alone would not be sufficient for a good resolution within the complex superfamily. It is likely that the inclusion of adult characters would have improved the results of the phylogenetic analyses. However, this would have been clearly beyond the scope of this study.

\section{MATERIAL AND METHODS}

List of taxa examined (fixed in $70 \%$ ethanol unless otherwise noted)

Tenebrionoidea, Melandryidae: Orchesia micans (Panzer, 1794) (Dubosq Brazil), Mycetoma sp., Xylita livida Sahlberg, 1883 (determined material provided by S.A. Ślipiński)

Mordellidae: Curtimorda sp., Tomoxia bucephala Costa, 1854 (prepupa) (determined material provided by S.A. Ślipiński)

Oedemeridae: Pseudolycus haemorrhoidalis (Fabricius, 1801) (determined by S.A. Ślipiński)

Pyrochroidae: Pyrochroa $\mathrm{sp} .(\mathrm{FAE}=$ formaldehyde + ethanol + acetic acid) (identified by R.G. Beutel)

Pythidae: Pytho niger Kirby, 1837 (Kahle's fluid) (determined material provided by D.A. Pollock)

Ulodidae: Meryx rugosa Latreille, 1807 (determined material provided by S.A. Ślipiński) 


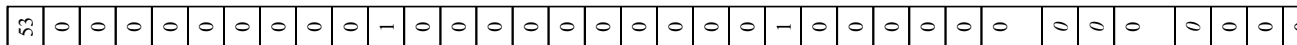

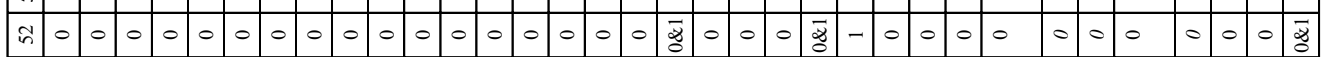
\begin{tabular}{|llllllllllllllllllllllllllllllllllll}
$\bar{n}$ & 0 & 0 & $\bar{z}$ & 0 & 0 & $\bar{z}$ & 0 & $\bar{z}$ & - & - & 0 & 0 & 0 & 0 & 0 & 0 & - & $\bar{z}$ & - & 0 & - & $\bar{z}$ & 0 & $\bar{z}$ & - & $\bar{z}$ & - & - & - & $\bar{z}$ & - & - & - & $\bar{z}$ \\
\hline
\end{tabular} \begin{tabular}{llllllllllllllllllllllllllllllllllllll}
\hline$n$ & 0 & 0 & $\bar{z}$ & 0 & 0 & $\bar{z}$ & 0 & $\bar{z}$ & 0 & 0 & 0 & 0 & 0 & 0 & 0 & 0 & 0 & $\bar{z}$ & 0 & 0 & 0 & 0 & 0 & 0 & 0 & 0 & 0 & 0 & 0 & 0 & 0 & 0 & 0 & 0 \\
\hline
\end{tabular}

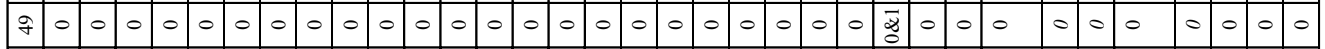
\begin{tabular}{|lllllllllllllllllllllllllllllllllllll}
\hline$\alpha$ & 0 & 0 & 0 & 0 & 0 & $\bar{z}$ & 0 & 0 & 0 & 0 & $\bar{z}$ & 0 & - & 0 & 0 & 0 & 0 & 0 & 0 & 0 & 0 & 0 & 0 & 0 & 0 & 0 & 0 & 0 & 0 & 0 & 0 & 0 & 0 & 0 \\
\hline
\end{tabular}

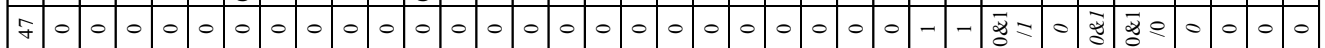

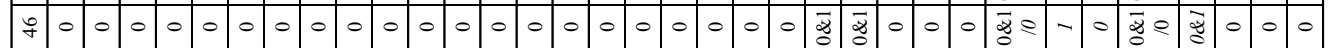

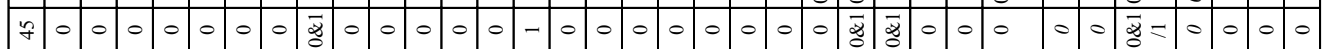

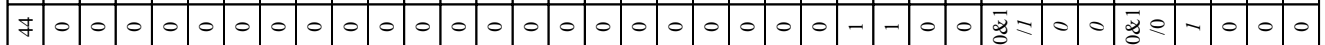

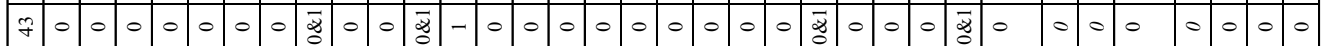

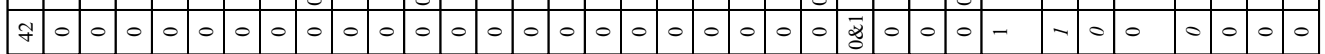
\begin{tabular}{|l|llllllllllllllllllllllllllllllllllllll}
\hline$z$ & 0 & 0 & 0 & 0 & 0 & $\bar{z}$ & 0 & 0 & $\bar{z}$ & 0 & $\bar{z}$ & 0 & 0 & 0 & 0 & 0 & 0 & 0 & $\bar{z}$ & 0 & 0 & 0 & 0 & 0 & 0 & 0 & 0 & 0 & 0 & 0 & 0 & 0 & 0 & 0 \\
\hline
\end{tabular}

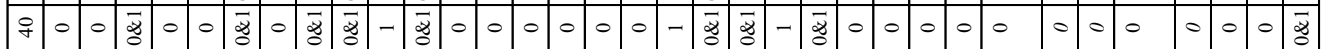

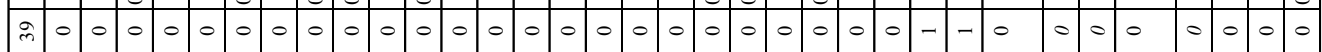

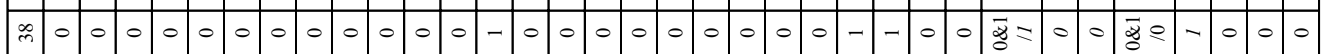

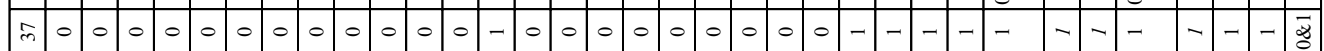

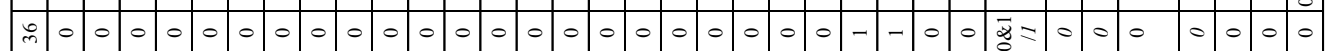
\begin{tabular}{llllllllllllllllllllllllllllllllllll}
$m$ & 0 & 0 & 0 & 0 & 0 & 0 & 0 & 0 & - & 0 & 0 & 0 & 0 & 0 & 0 & 0 & 0 & 0 & 0 & 0 & 0 & 0 & 0 & 0 & 0 & 0 & 0 & 0 & 0 & 0 & 0 & 0 & 0 & 0 \\
\hline
\end{tabular}

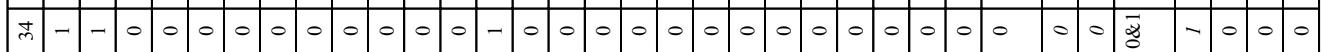

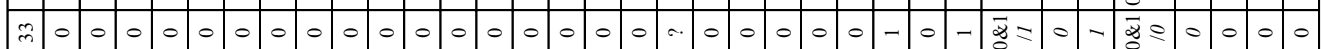

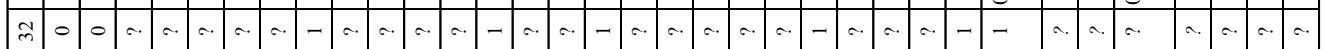

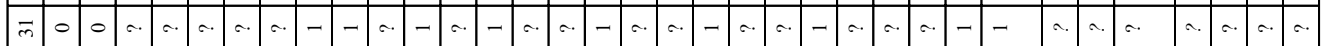
\begin{tabular}{llllllllllllllllllllllllllllllllllllllll}
\hline$m$ & 0 & 0 & 0 & - & - & 0 & $\bar{z}$ & 0 & 0 & 0 & $\cdots$ & 0 & 0 & - & $\bar{z}$ & - & $\cdots$ & $\cdots$ & 0 & - & 0 & - & 0 & 0 & - & - & $\bar{z}$ & 0 & 0 & - & $\bar{z}$ & 0 & 0 & 0 & 0 & $\bar{z}$ \\
\hline
\end{tabular}

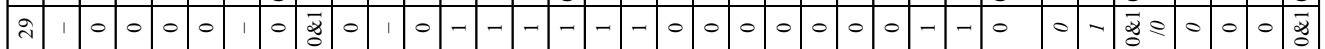

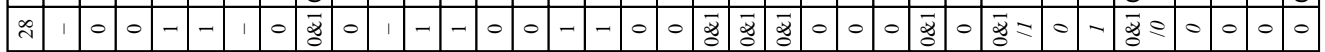

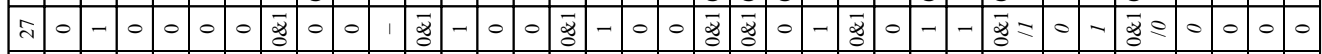

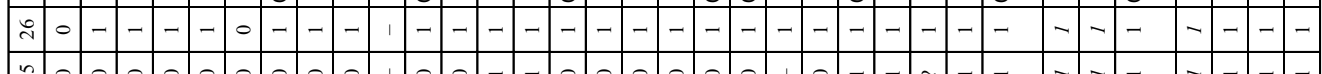

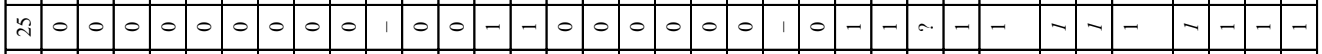
\begin{tabular}{|l|llllllllllllllllllllllllllllllllllll}
\hline & 0 & 0 & 0 & 0 & 0 & $\bar{z}$ & 0 & 0 & 0 & - & 0 & 0 & 0 & 0 & 0 & 0 & 0 & 0 & 0 & 0 & - & 0 & 0 & 0 & 0 & 0 & 0 & 0 & 0 & 0 & 0 & 0 & 0 & 0 \\
\hline
\end{tabular}

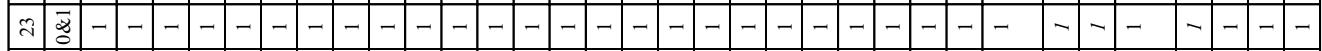

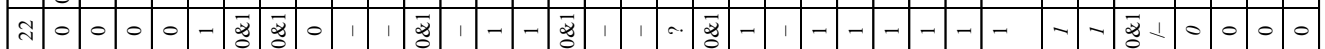

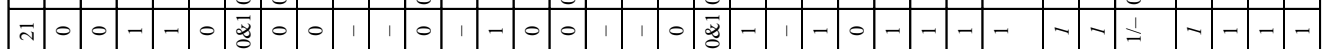

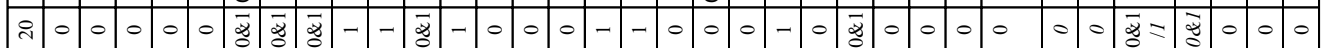

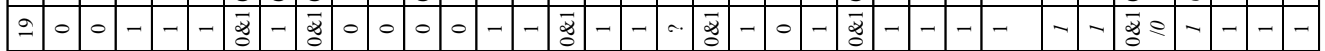

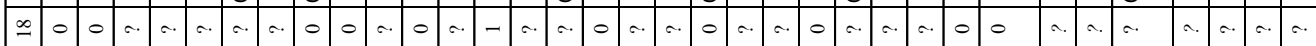

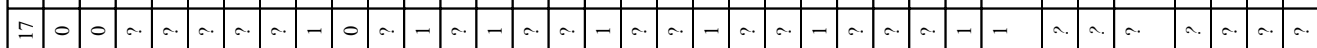

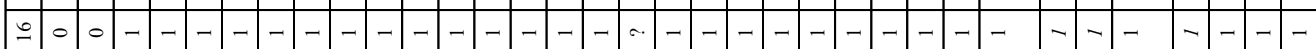
$\because \bar{z}$\begin{tabular}{llllllllllllllllllllllllllllllllllll}
\hline & 0 & 0 & 0 & 0 & - & 0 & 0 & 0 & 0 & 0 & 0 & 0 & 0 & 0 & 0 & 0 & 0 & $\bar{z}$ & 0 & 0 & 0 & 0 & 0 & - & - & 0 & $\cdots$ & 0 & 0 & 0 & 0 & $\cdots$ & 0 \\
\hline
\end{tabular}

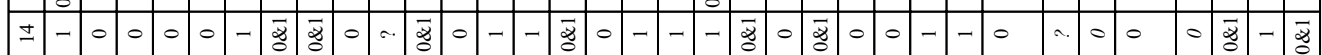

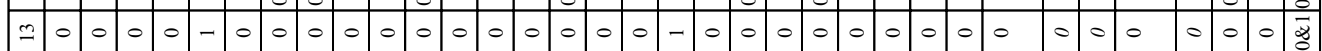
\begin{tabular}{|lllllllllllllllllllllllllllllllllllllllll}
\hline$I$ & 0 & 0 & 0 & 0 & 0 & 0 & $\bar{z}$ & 0 & 1 & 0 & 0 & 0 & 0 & 0 & 0 & 0 & 0 & 0 & 0 & 0 & 0 & 0 & 0 & 0 & 0 & 0 & 0 & 0 & 0 & 0 & 0 & 0 & 0 & 0 \\
\hline
\end{tabular}

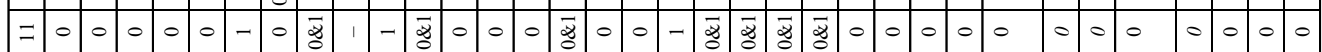

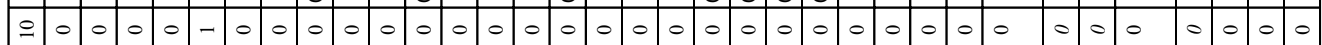

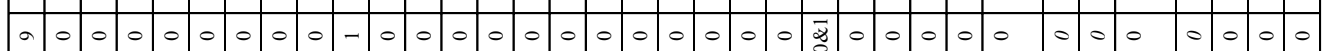

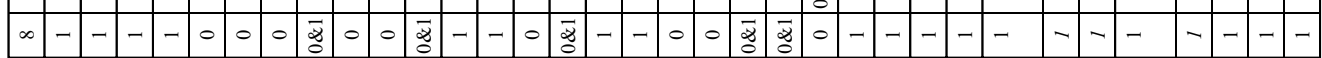

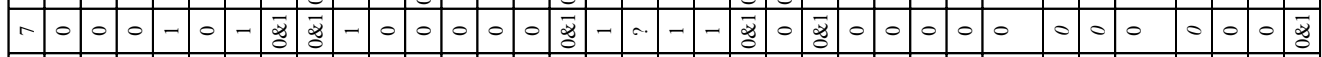

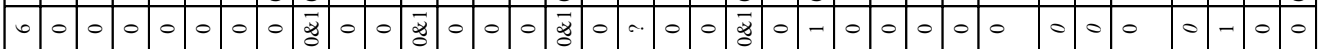

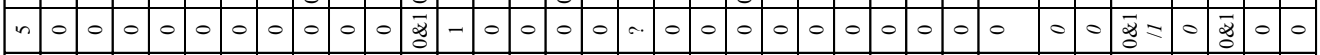

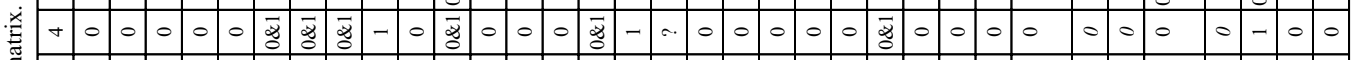

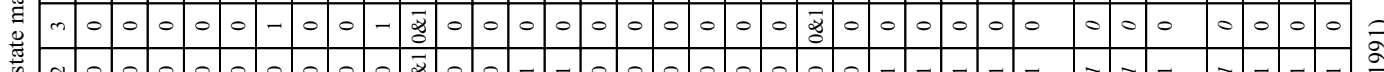

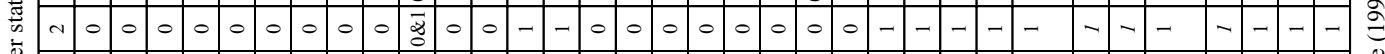

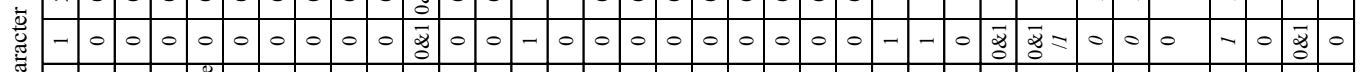

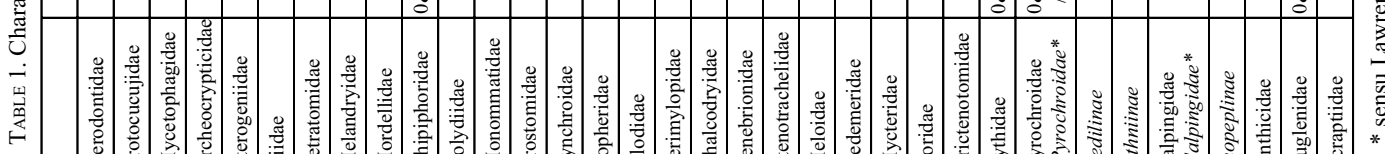


Prostomidae: Prostomis mandibularis (Fabricius, 1801) (Dubosq Brazil) (identified by R. Britz)

Colydiidae: Bitoma crenata (Fabricius, 1775) (FAE) (identified by R.G. Beutel)

Cleroidea, Phycosecidae: Phycosecis litoralis (Pascoe, 1875) (determined material provided by J.F. Lawrence)

Cucujoidea, Sphinididae: Sphindus americanus LeConte, 1866 (determined material provided by J.F. Lawrence)

Protocucujidae: Ericmodes sp. (Chile) (determined material provided by J.F. Lawrence)

Lymexyloidea, Lymexylidae: Hylecoetus dermestoides (Linnaeus, 1761) (Dubosq Brazil) (identified by R.G. Beutel).

Derodontoidea, Derodontidae: Derodontus esotericus Lawrence, 1979 (determined material provided by R.A.B. Leschen).

\section{Morphology and phylogenetic analyses}

Larval specimens of Orchesia micans, Mycetoma sp., Pseudolycus sp., Pseudolycus haemorrhoidalis, Pytho niger, Prostomis mandibularis, Curtimorda sp., Tomoxia sp., Meryx rugosa, Silvanus sp., Hylecoetus dermestoides and Derodontus esotericus were imbedded in Historesin, cut at $3 \mu \mathrm{m}$ and stained with methylene-blue and acid fuchsine. Drawings were made using an ocular grid or a camera lucida (cross sections). For SEM micrographs (FEI ESEM XL 30) specimens were cleaned ultrasonically, dried (critical point) and coated with gold.

The classification used here is based on Lawrence \& Newton (1995) and von Kéler's muscular nomenclature is used in the text and the corresponding numbers in the illustrations (v. Kéler, 1963).

The data were coded as binary characters and entered into Winclada (Nixon, 1999). All characters were equally weighted. Tree searches were done in NONA (Goloboff, 1999). The trees were rooted automatically while executing the search (Nixon \& Carpenter, 1993). The data matrix is provided in Table 1.

Salpingidae and Pyrochroidae as defined by Lawrence \& Newton (1995) were treated as terminal taxa in the first analysis. Inopeplinae, Othniinae, Salpingidae sensu Lawrence (1991), Pedilinae and Pyrochroidae sensu Lawrence (1991) were treated as terminals in the second analysis (entries in italics in the data matrix; Table 1).

\section{MORPHOLOGICAL RESULTS}

\section{Orchesia micans (Melandryidae)}

1.1. General appearance (Fig. 1a). Length of last instar larvae 5.3-6.7 mm $(\mathrm{n}=6)$. Head shiny and of very light brown colour, with strongly sclerotised parts darkened; other parts of body largely unpigmented or yellowish in mature larvae. Legs well developed. Body slightly curved in lateral view and sub-cylindrical, posterior abdomen almost cylindrical. Abdomen about 2.4 times longer than thorax, segments V and VI slightly broader than other segments. Urogomphi absent.

1.2. Head capsule, external features (Figs 1a, 2a, 3a, 4a, 6a, 7a). Slightly retracted into prothorax. Shape of head almost semispherical, distinctly rounded laterally, with short and flat ventral side and strongly arched dorsal side (Figs 1a, 2a, 3a). Ventral mouthparts horizontal, mandibles slightly inclined (Fig. 2a). Setation as shown in Figs 1a, 2a and 4a. Antenna inserted below narrow anterolateral extension of head capsule. Five small stemmata present, arranged in an oblique row of 3 posterior to antennal insertion and 2 widely separated stemmata on the posterior genal region (Fig. 2a). Labrum moveable,
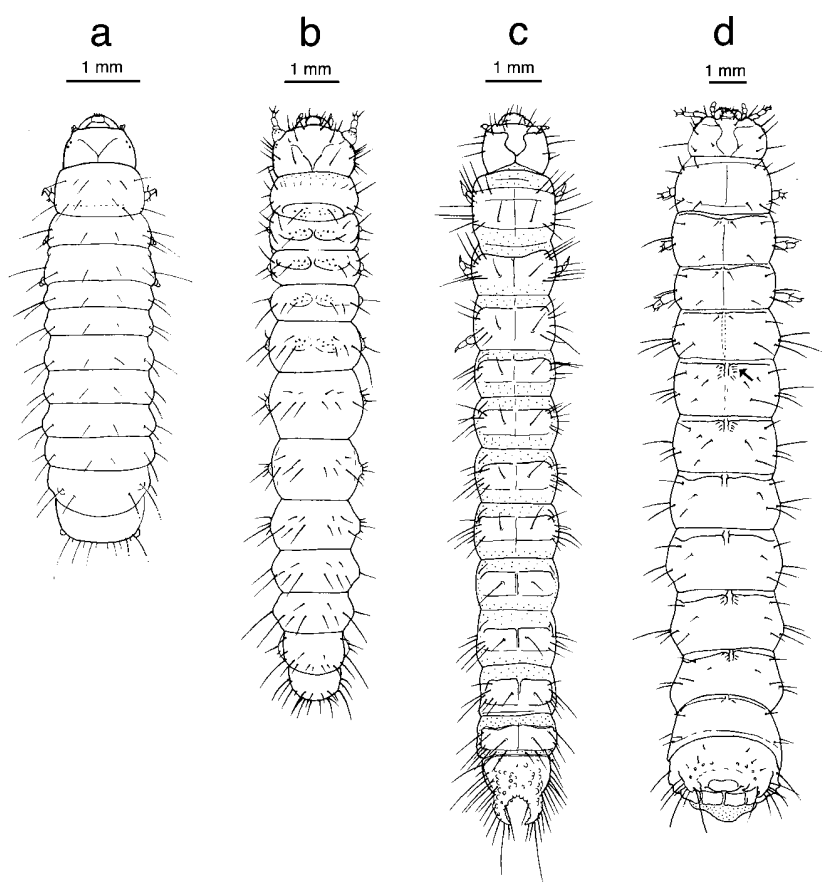

Figs 1a-d: Larval habitus, dorsal view. a - Orchesia micans; b - Pseudolycus haemorrhoidalis; c - Meryx rugosa; d - Pytho niger, urogomphal plate deflexed dorsally; arrow indicates process of anterior ridge.

connected to clypeus by a membranous fold (Figs 3a, 6a). Clypeus transparent, trapezoidal, very distinctly separated from strongly sclerotised anterior margin of frons (Fig. $3 a)$. Frons elongated. Frontal suture (= frontal arms) V-shaped, strongly diverging anteriorly, obliterated anterolaterally. Coronal suture (= epicranial stem) moderately short. Median endocarina present, coincident with coronal suture posteriorly. Hypostomal rods distinct, forked, external branches short, internal branches converging (Fig. 7a). Ventral epicranial ridges absent. Maxillary grooves well developed, anteriorly closed by a broad, exposed supramaxillary bridge (Figs 4a, 7a). Gula short, completely fused with submentum anteriorly, posteriorly covered by sclerotised anterior prosternal plate together with posteroventral area of head capsule. Gulasubmentum strongly constricted between maxillary bases (Fig. 4a).

1.3. Head capsule, internal skeletal structures (Figs 5a, 7a). Strong apodeme arises from the median endocarina anteriorly. Anteriorly converging internal gulasubmental ridges continuous with well developed postoccipital ridges. Tentorium strongly reduced (Figs 5a, 7a). Posterior arms arise from gulasubmental ridges posterior to maxillary fossa. Tentorial bridge, dorsal arms and anterior arms absent.

1.4. Labrum (Figs 3a, 5a, 6a). Distinctly inclined (Fig. 5a), fairly narrow, with rounded anterolateral edges and a slightly convex anterior margin. Setation as shown in Figs $3 \mathrm{a}$ and $6 \mathrm{a}$.

Musculature (Figs 5a, 6a): M 7: M. labroepipharyngalis, not indentified on microtome sections, probably absent; M 9: M. frontoepipharyngalis, very large muscle, $\mathrm{O}$ (= origin): anterior apodeme of median endocarina, I (= 

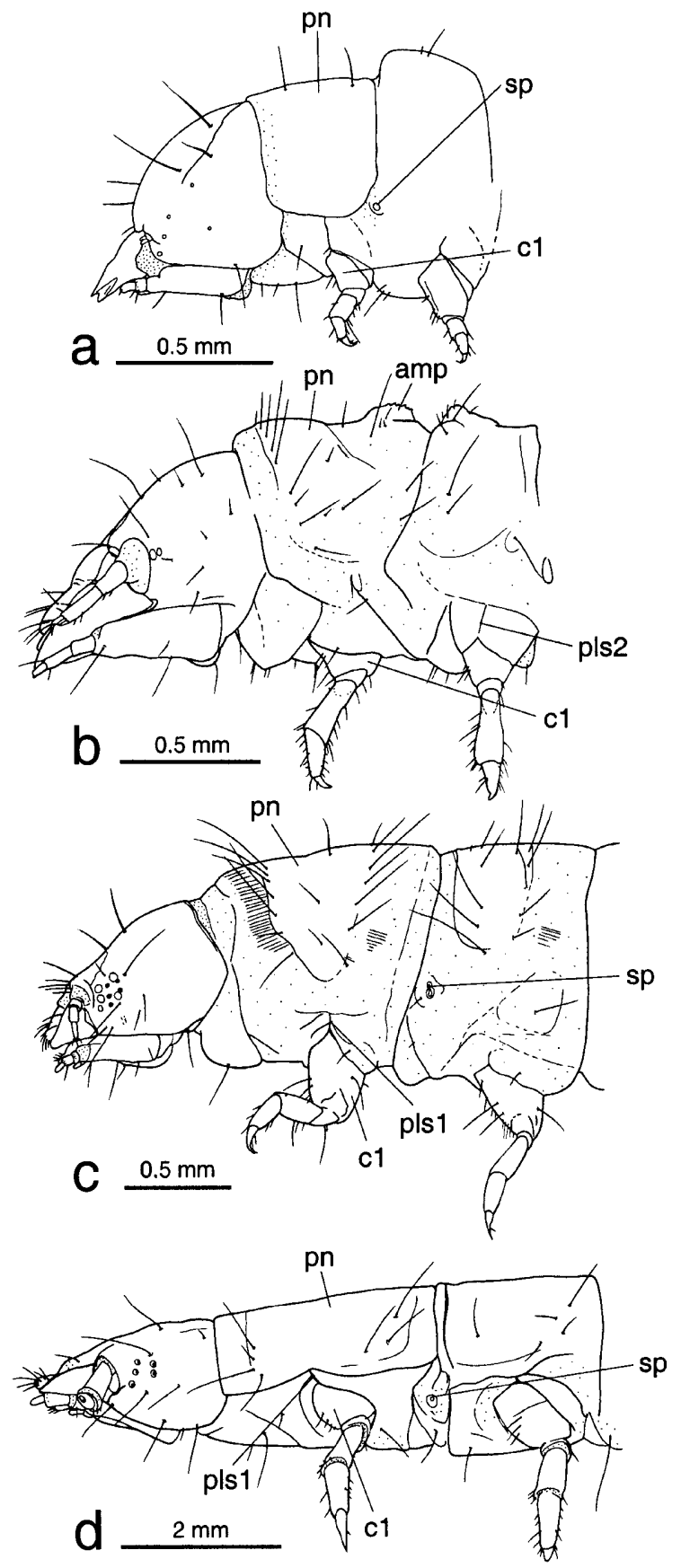

Figs 2a-d: Head, pro- and mesothorax. a - Orchesia micans; $\mathrm{b}-$ Pseudolycus haemorrhoidalis; $\mathrm{c}$ - Meryx rugosa; $\mathrm{d}-$ Pytho niger. Abbreviations: amp - ampulla, c1 - procoxa, pls1/2 pro/mesopleural suture, $\mathrm{pn}$ - pronotum, $\mathrm{sp}$ - spiracle.

insertion): medially on epipharynx, close to insertion of anterior component of $\mathrm{M} 43$.

1.5. Antenna (Figs 2a, 4a). Extremely short, with only two apparent antennomeres. Ventrally directed, not visible from above (see above; Figs 2a, 4a). Sensorial appendage well developed, as long as terminal segment.

Musculature (Figs 6a, 8): Mm 1, 2, 4: M. tentorioscapalis anterior, posterior, medialis, $\mathrm{O}$ : dorsal wall of head capsule, I: anteroventrally, posteriorly, and dorsally on the base of antennomere I.
1.6. Mandible (Figs 2a, 4a, 5a, 6a). Symmetrical, roughly triangular, with bidentate distal part and a distinct external furrow between the two apices (Fig. 2a). Mesal edge with small bidentate tooth. Prostheca absent. Typical mola not developed, molar area without tubercles or ridges (Fig. 6a).

Musculature (Figs 5a, 8): M 11: M. craniomandibularis internus, large muscle, O: median endocarina, dorsolateral, lateral, and ventrolateral areas of the head capsule, $\mathrm{I}$ : adductor tendon; $\mathrm{M}$ 12: $\mathrm{M}$. craniomandibularis externus, O: lateral wall of head capsule, I: abductor tendon.

1.7. Maxilla (Figs 4a, 7a, 8). Inserted in a well developed fossa maxillaris, which is anteriorly closed by a broad supramaxillary bridge (Fig. 7a). Articulatory area partly semimembranous, lightly sclerotised posteriorly, but not pad-like. Cardo transverse, undivided, connected with stipes by a hinge. Mala rounded, not cleft, and without tooth, with an anteriorly directed group of apical setae, a strong, subapical, mesally directed seta (Fig. 7a), and a regular subapical row of dorsomesally directed setae. Palp 3-segmented, moderately long. Distinct palpifer not developed. Palpomeres I-III about equally long. Distal palpomere apically rounded.

Musculature (Figs 7a, 8): M 15: M. craniocardinalis, absent; Mm 17/18: Mm. tentoriocardinalis and - stipitalis, several large bundles, O: posterior tentorial arm, I: ventral surface of cardo and stipes and mesal stipital edge; M 19: M. craniolacinialis, one large bundle, O: laterally from head capsule, I: base of mala; Mm 22/23: M. stipitopalpalis externus and internus, $\mathrm{O}$ : ventral surface of stipes, I: base of maxillary palp.

1.8. Labium (Figs 4a, 5a, 8). Submentum completely fused with gula posteriorly (see above), distinctly constricted between maxillary bases. Mentum moderately long, only indistinctly separated from gulasubmentum, inserted between maxillary apices, anterolaterally continuous with the supramaxillary bridge. Prementum very small, with 2-segmented, short palps. Ligula present, large, forming sclerotised edge anterior to apices of labial palps.

Musculature (Figs 5a, 8): M 28: M. submentopraementalis, absent; M 29: M. tentoriopraementalis inferior, one moderately large, almost vertical bundle, O: apical part of posterior tentorial arm, I: ventromesally on hind margin of prementum; M 30: M. tentoriopraementalis superior, absent; M 34: M. praementopalpalis externus, absent; M. submentogularis transversalis (homology unclear): a very large muscle which connects the submentogular ridges (Fig. 8a).

1.9. Epipharynx (Figs 5a, 6a). Anterior part, i.e. ventral side of labrum unsclerotised, very slightly concave, posteriorly bordered by a very strong transverse fold, with dense lateral fields of microtrichiae. Intermediate epipharyngeal part distinctly convex in cross section, with very strong paramedian longitudinal sclerotised rods and longitudinal lateral folds. Posterior part forms a preoral chamber together with the mandibles and the hypopharynx, and a very short prepharyngeal tube by fusion with 


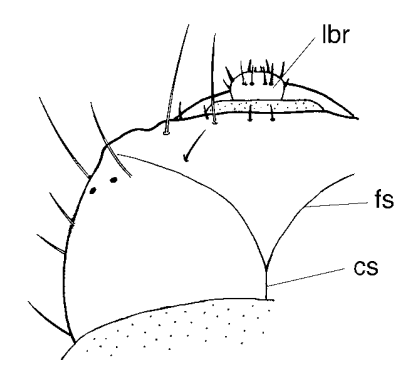

a $\quad 0.2 \mathrm{~mm}$

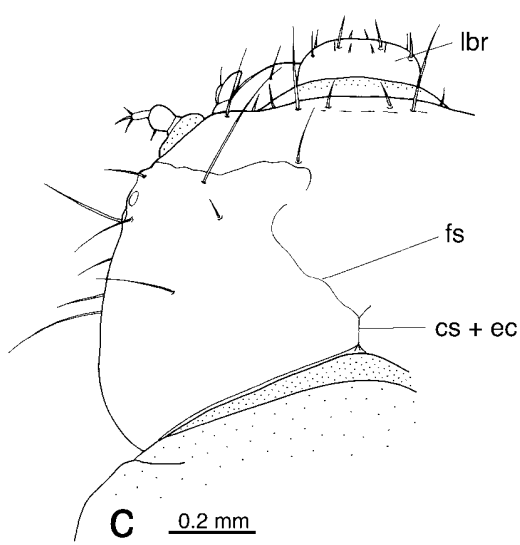

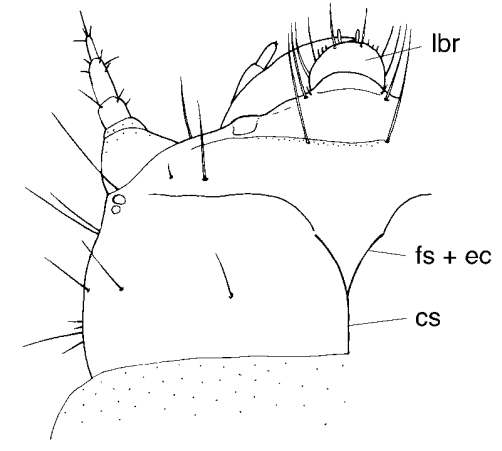

b $\quad 0.4 \mathrm{~mm}$

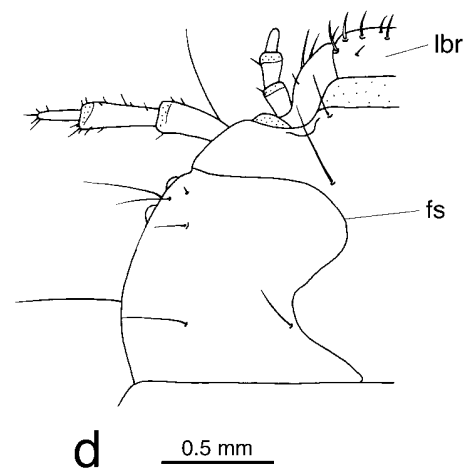

Figs 3a-d: Head, dorsal view. a - Orchesia micans; $\mathrm{b}$ - Pseudolycus haemorrhoidalis; $\mathrm{c}$ - Meryx rugosa; $\mathrm{d}$ - Pytho niger. Abbreviations: $\mathrm{cs}$ - coronal suture (= epicranial stem), ec - endocarina, fs - frontal suture, lbr - labrum.

the lateral margin of the posterior hypopharynx anterior to the anatomical mouth.

Musculature (Figs 5a, 6a, 8c, d): M 43: M. clypeopalatalis, well developed, composed of 3 bundles, O: anterior frons, anterior to M 45, I: epipharynx, paramedially, anterior to attachment of $\mathrm{M} 41$.

1.10. Hypopharynx (Figs 5a, 8c, d). Anterior part continuous with dorsal side of prementum, devoid of pubescence. Posterior part convex in cross section, laterally fused with epipharynx anterior to anatomical mouth (see above).

Musculature (Figs 5a, 8): M 41: M. frontohypopharyngalis, a single flat and unusually thin bundle; $\mathrm{O}$ : central area of frons, I: posterolaterally on hypopharynx by means of a strong tendon; M 42m: $M$. tentoriohypopharyngalis medialis, absent; $M$ 421: $M$. tentoriohypopharyngalis lateralis: absent.

1.11. Pharynx (Figs 5a, 8a, b). Moderately wide, lateral, dorsal, and ventrolateral folds indistinct posteriorly, more distinct in the anterior part of the pharynx. Anteriormost part continuous with short prepharyngeal tube, connected with supramaxillary bridge area by fibrillar structures.

Musculature (Figs 5a, 8a, b): M 45: M. frontobuccalis anterior, a thin bundle, $\mathrm{O}$ : frons, posterior to $\mathrm{M} 43$, I: anatomical mouth; $\mathrm{M}$ 46: $\mathrm{M}$. frontobuccalis posterior, a series of bundles, $\mathrm{O}$ : posterior frons, lateral to $\mathrm{M}$. frontoepipharyngalis, I: dorsolaterally on pharynx; M 51: $\mathrm{M}$. verticopharyngalis, absent; M 52: M. tentoriopharyngalis, rather thin muscle with atypical origin, $\mathrm{O}$ : ventrolaterally from postoccipital ridge, I: ventrolaterally on posterior pharynx.

Unusually well developed ring musculature present over the whole length of the pharynx (Fig. 5a).

1.12. Cerebrum suboesophageal complex (Fig. 5a). Fairly small in relation to size of head capsule. Posterior part of cerebrum not extending posteriorly into the prothorax.

1.13. Glands (Fig. 5a). A pair of coiled, tube-like glands with asymmetric position originates in the prothorax. They appear to open ventrolaterally close to the premental base. However, the exact distal orifice could not be identified.

1.14. Fat body. Only few and small sheets of fat body tissue present within head capsule (Fig. 8).

1.15. Prothorax (Figs 1a, 2a, 10a). Slightly longer than following thoracic segments (Figs 1a, 2a, 10a). Tergite distinct, sclerotised and shiny, extending to pleural area, with semimembranous margin. Laterotergite not distinctly developed. Sternum sclerotised, divided into distinctly separated parts. Large anteromedian plate, probably composed of the presternum + cervicosternum, covers posterior gular area. Basisternum broad, not separated from episternum (Fig. 10a). Sternellum inserted between coxae, separated from basisternum by a very distinct furrow. Precoxale and postcoxale not recognisable as separate sclerites. Pleural suture above coxal cavity distinct, fairly short, reaching semimembranous margin of 


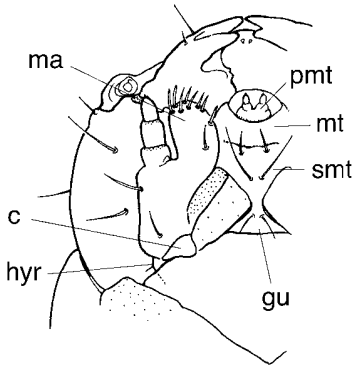

a

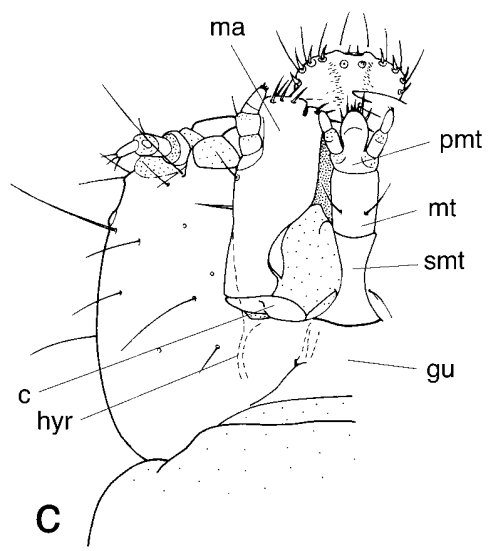

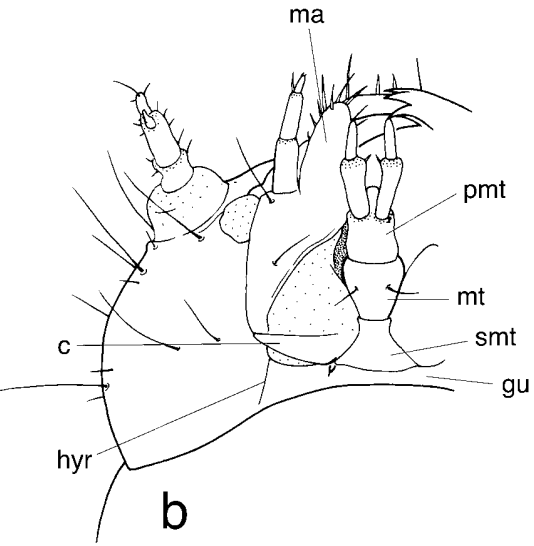

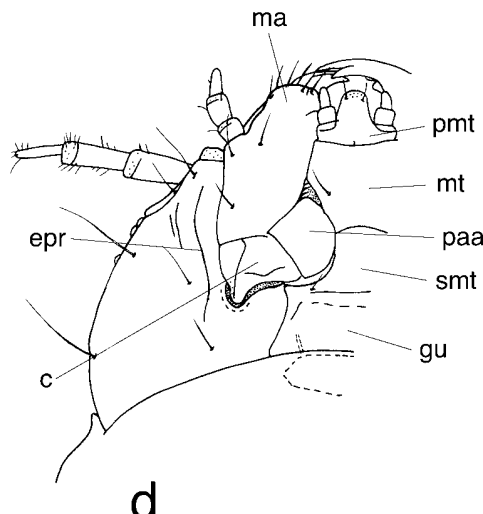

Figs 4a-d: Head, ventral view. a - Orchesia micans; $\mathrm{b}$ - Pseudolycus haemorrhoidalis; $\mathrm{c}$ - Meryx rugosa; $\mathrm{d}$ - Pytho niger. Abbreviations: c - cardo, epr - ventral epicranial ridge, gu - gula, hyr - hypostomal ridge, ma - mala, md - mandible, mt - mentum, paa pad-like articulatory area, pmt - prementum, smt - submentum.

protergum. Legs widely separated, 5-segmented, composed of conical coxa with distinct anterolateral and posterolateral longitudinal ridges, well developed trochanter, femur, tibiotarsus, and a strong pretarsal claw with one seta (Figs 2a, 10a).

1.16. Mesothorax (Figs 1a, 2a). Slightly shorter and broader than prothorax. Tergum less distinctly delimited laterally, slightly bulging dorsally (Fig. 2a), but without well defined transverse ampulla. Sternal plate undivided, with indistinct apophysal pits, laterally fused with episternum and epimeron. Pleural suture distinct and fairly long. Annular stigma located near posterolateral edge of protergum, not elevated. Legs similar to prothoracic legs, coxa slightly longer (Fig. 2a).

1.17. Metathorax (Fig. 1a). Similar to mesothorax in shape and extension, without stigma. Tergum slightly longer than mesotergite and less distinctly bulging (Fig. 1a).

1.18. Abdominal segments I-VI (Fig. 1a). Segments I-VI about equally long, with moderately distinct semimembranous lateral bulges. Ampullae absent from dorsal side. Sternites sclerotised. Tergites also sclerotised, but without well defined lateral margins.

1.19. Abdominal segment VII (Fig. 1a). Tergum distinctly elongated posteriorly.

1.20. Abdominal segment VIII (Figs 1a, 11a). With large tergum and a pair of small posterolateral protuberances.
1.21. Abdominal segments IX and $X$ (Fig. 11a). Tergum roughly semicircular and in almost vertical position due to posterior extension of terga VII and VIII. Sternum short. Urogomphi absent. Small, transverse segment $\mathrm{X}$ enclosed between tergum and sternum of segment IX, ventrally oriented.

1.22. Spiracles. Annular-biforous, with short accessory tubes.

\section{Pseudolycus haemorrhoidalis (Oedemeridae)}

2.1. General appearance (Fig. 1b). Length of last instar larvae 9.5-11.5 mm $(\mathrm{n}=4)$. Very lightly coloured or unpigmented. Body elongate, almost cylindrical, abdomen at least 3.5 times longer than thorax. Legs well developed. Urogomphi absent.

2.2. Head capsule, external features (Figs 2b, 3b, 4b). Cream coloured or testaceous except for mandibular apex, slightly retracted into prothorax, very slightly inclined, almost prognathous (Fig. 2b), moderately flattened, slightly rounded laterally, symmetrical. Dorsal side of sclerotised head capsule longer than ventral side. Setation as shown in Figs 2 b, $3 b$ and $4 b$. Two small stemmata present posterior to antennal base. Antenna inserted anterolaterally on a very prominent, largely sclerotised articulating area. Labrum moveable, separated from clypeus by a membranous fold (Figs 4b, 5b). Clypeal area sclerotised, strongly convex anteromedially, indistinctly separated from frontal area by a membranous transverse 

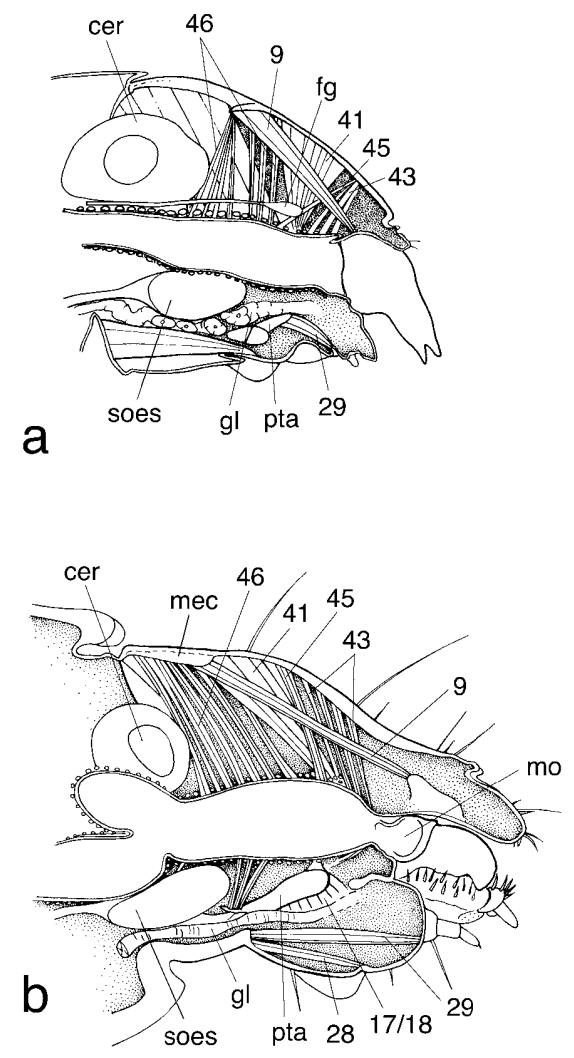
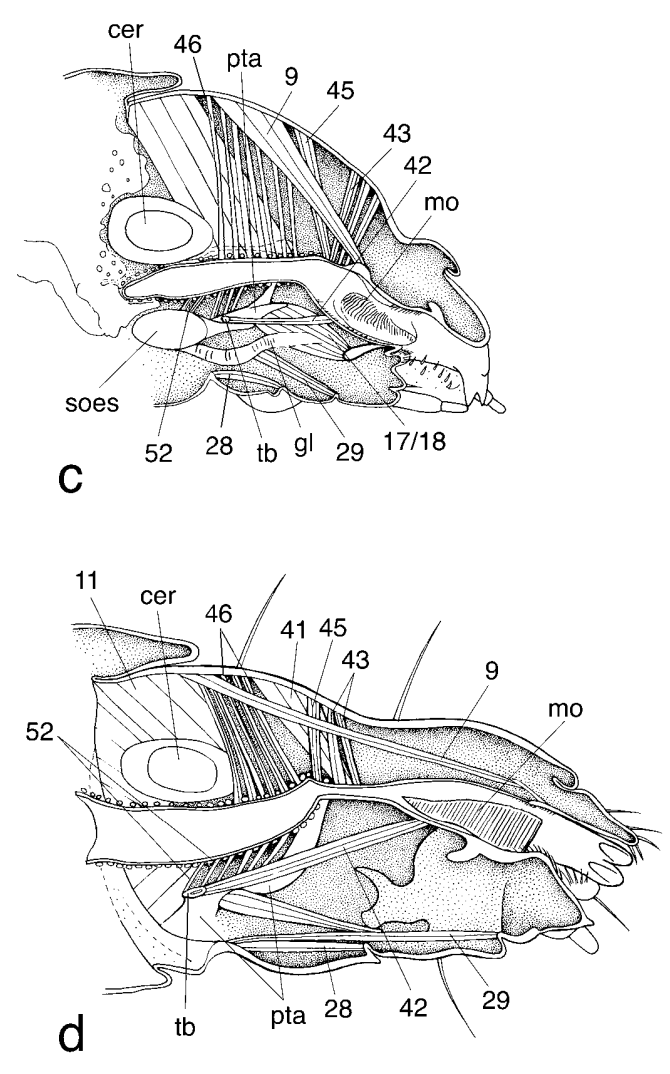

Figs 5a-d: Head, sagittal section. a - Orchesia micans; b - Pseudolycus haemorrhoidalis; $\mathrm{c}$ - Meryx rugosa; $\mathrm{d}$ - Pytho niger. Abbreviations: cer - cerebrum, fg - frontal ganglion, gl - tube-like salivary glands, mec - median endocarina, mo - mola, ph - pharynx, pta - posterior tentorial arm, soes - suboesophageal complex, tb - tentorial bridge, $9-\mathrm{M}$. frontoepipharyngalis, $11-\mathrm{M}$. craniomandibularis internus, $17-$ M. tentoriocardinalis, $18-$ M. tentoriostipitalis, $28-$ M. submentopraementalis, $29-$ M. tentoriopraementalis inferior, $41-\mathrm{M}$. frontohypopharyngalis, $42-\mathrm{M}$. tentoriohypopharyngalis medialis, 43 - M. clypeopalatalis, 45-M. frontobuccalis anterior, $46-\mathrm{M}$. frontobuccalis posterior, $52-\mathrm{M}$. tentoriopharyngalis.

line. Frontal suture V-shaped, meeting at a narrow angle, strongly diverging anteriorly, obliterated anterolaterally. Coronal suture moderately long. Dorsal endocarina present, Y-shaped, coincident with coronal suture and posterior part of frontal sutures. Hypostomal rods present, ventral epicranial ridges absent. Maxillary grooves well developed. Gula present, short, fairly broad, converging anteriorly (Fig. 4b). Posteriorly covered by sclerotised anterior prosternal plate. Posterior tentorial grooves distinctly visible at gula-submental border.

2.3. Internal skeletal structures (Figs 5b, 6b). Anteriorly converging gular ridges continuous with developed postoccipital ridges posteriorly. Anterior part high, connected by well developed tentorial bridge (Fig. 6b), anteriorly continuous with strong posterior tentorial arms (Fig. 6b). Posterior arms strongly converging anteriorly. Dorsal arms not identified, extremely reduced or absent. Anterior arms present, attached to head capsule mesad to origin of antennal muscles (Fig. 5b).

2.4. Labrum (Figs 3b, 4b, 5b, 6b). Well developed, but narrow, convex anteromedially, connected with clypeus by a membranous fold, with a pair of paramedian, very strong setae at anterior margin. Other setae as shown in Figs $3 b$ and $4 b$.
Musculature (Figs 5b, 6b): M 7: M. labroepipharyngalis, absent; M 9: frontoepipharyngalis, strong muscle, $\mathrm{O}$ : posteriormost frons, between bases of diverging arms of endocarina, I: medially on anterior epipharynx.

2.5. Antenna (Figs 3b, 4b). Fairly short, 3-segmented, ventrally directed. Distal membranous part of articulating area appears antennomere-like in dorsal view. Proximal antennomere about 2.5 times longer than wide, antennomere II 3.5 times longer than wide, with ventrally inserted well developed sensorial appendage. Apical antennomere distinctly smaller than preceeding segments, about twice as long as sensorial appendage.

Musculature (Fig. 6b): Mm 1, 2, 4: M. tentorioscapalis anterior, posterior, medialis, O: dorsal wall of head capsule, lateral to anterior end of endocarina, very close to attachment of anterior tentorial arm (Fig. 6b); I: anteroventrally, posteriorly, and dorsally on the base of antennomere I.

2.6. Mandible (Figs 2b, 6b, 12a). Asymmetrical, fairly broad at base, with slender, bidentate apical part. Distinct subapical tooth present on ventral edge and less distinct subapical tooth on dorsal edge. Prostheca absent. Mola present, distinctly delimited and very strongly sclerotised, with very distinct, slightly oblique, parallel ridges (Fig. $6 b)$. Left mola with very distinct molar tooth. 

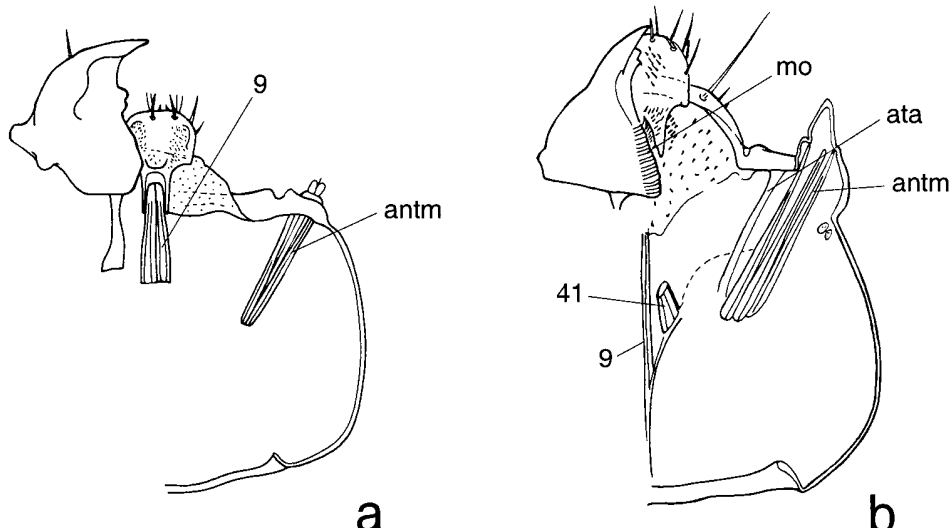

a

b

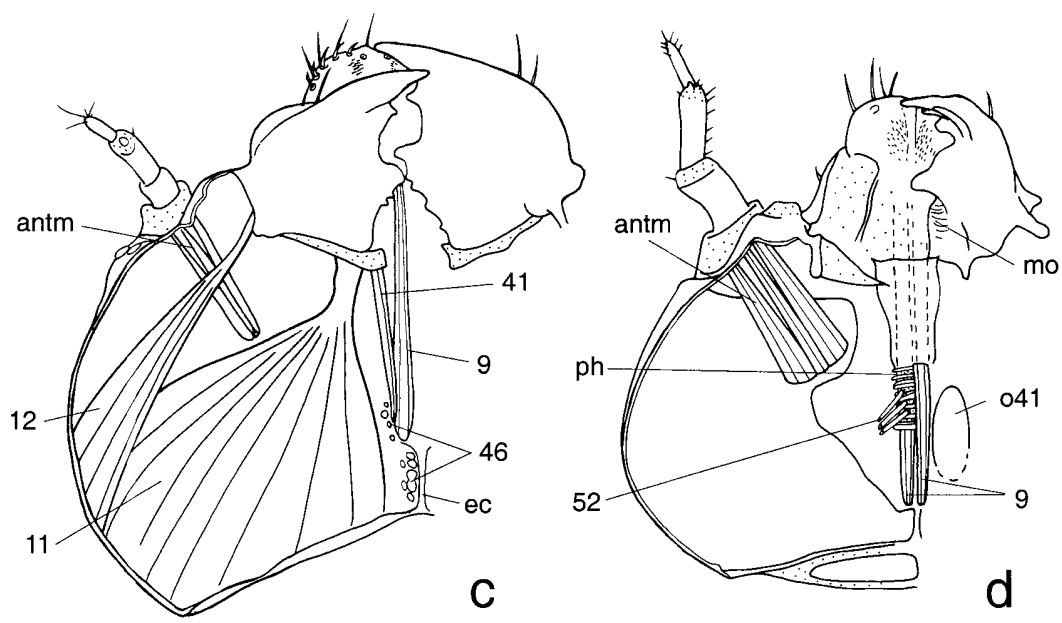

Figs 6a-d: Head, horizontal section, dorsal part. a - Orchesia micans; b - Pseudolycus haemorrhoidalis; c - Meryx rugosa; d Pytho niger. Abbreviations: antm - antennal muscles, ata - anterior tentorial arms, ec - endocarina, mo - mola, o41 - origin of M. frontohypopharyngalis, $\mathrm{ph}$ - pharynx, $9-\mathrm{M}$. frontoepipharyngalis, $11-\mathrm{M}$. craniomandibularis internus, $12-\mathrm{M}$. craniomandibularis externus, $41-\mathrm{M}$. frontohypopharyngalis, $46-\mathrm{M}$. frontobuccalis posterior, $52-\mathrm{M}$. tentoriopharyngalis.

Musculature (Fig. 5b): M 11: M. craniomandibularis internus, very large and complex muscle, $\mathrm{O}$ : extensive dorsal, dorsolateral, and ventrolateral areas of the head capsule, I: adductor tendon; M 12: M. craniomandibularis externus, O: lateral wall of head capsule, I: abductor tendon.

2.7. Maxilla (Figs 4b, 7b). Inserted in a well developed fossa maxillaris. Articulatory area not pad-like (Fig. 4b). Cardo transverse, undivided, connected with stipes by a hinge. Mala rounded anteriorly, not cleft, with distinct subapical tooth (Figs 4b, 7b). An apical group of strong setae is directed anteriorly and two rows of mesally directed spines are present along the mesal margin of the mala. Palp 3-segmented, slightly longer than mala. Palpifer indistinct. Palpomeres I-II elongate, palpomere II slenderer than I. Distal palpomere less than half as long as II and III, conical, apically rounded, with minute apical sensillae.

Musculature (Fig. 7b): M 15: M. craniocardinalis, represented by a very thin muscle between the two bundles of M 19, O: together with M 19, I: thin tendon; Mm 17/18: Mm. tentoriocardinalis and - stipitalis, several strong bundles, O: posterior tentorial arm, I: ventral surface of cardo and stipes and mesal stipital edge; M 19: M. craniolacinialis, $\mathrm{O}$ : ventrolaterally from postoccipital ridge, I: base of mala; $\mathrm{Mm}$ 22/23: M. stipitopalpalis externus and internus, two parallel bundles, O: ventral surface of stipes, I: base of maxillary palp.

2.8. Labium (Figs 4b, 5b, 7b). Submentum separated from gula by slightly curved line, moderately constricted between maxillary bases. Mentum free to narrow basal part, slightly widening anteriorly. Prementum narrow and parallel sided. Palp 2-segmented, palpomere I long, slightly widening distally. Palpomere II slender, more than half as long as proximal segment, with minute apical sensilla. Ligula well developed, dorsomedially inserted between palps.

Musculature (Fig. 5b): M 28: M. submentopraementalis, O: posteromedially on submentum, I: ventromedially on posterior mental margin; M 29: M. tentoriopraementalis inferior, two parallel bundles, $\mathrm{O}$ : mesally from base of posterior tentorial arm, I: medially on ventral wall of prementum; M 30, M. tentoriopraementalis superior, absent or part of the previous muscle; M 34: M. praementopalpalis externus, absent.

2.9. Epipharynx (Fig. 6b). Anterior part of open cibarium, i.e. ventral side of labrum, sclerotised and shiny, moderately convex, with dense median field of microtrichiae. Posterior part with distinct median ridge, strong spines and two pairs of longitudinal sclerotisations. Lon- 


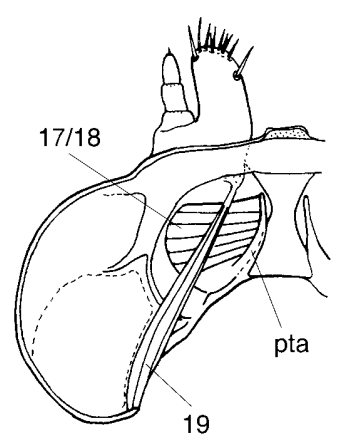

a

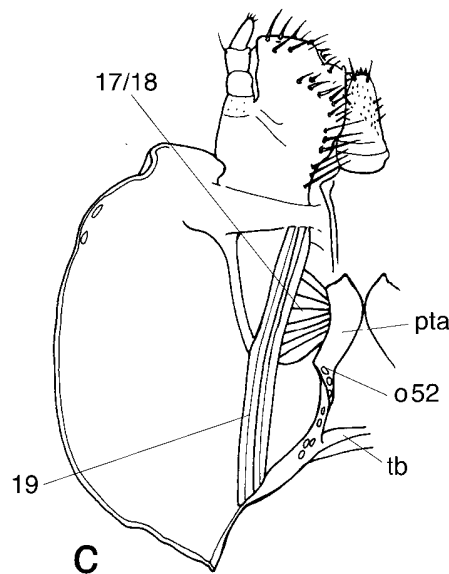

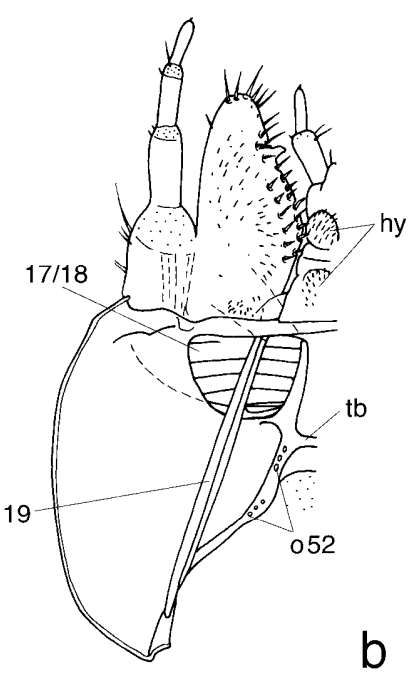

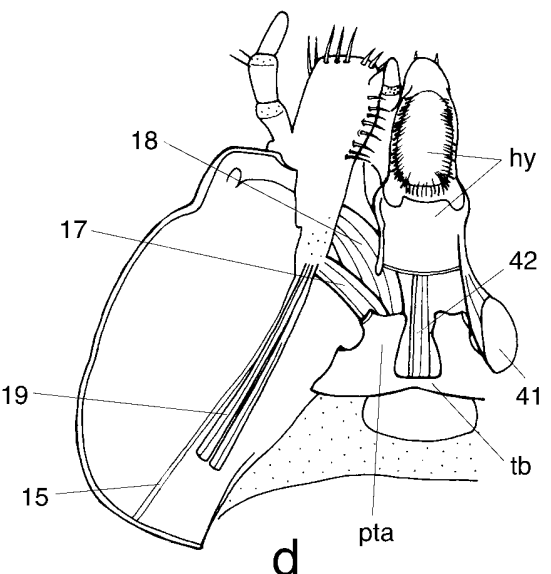

Figs 7a-b: Head, horizontal section, ventral part. a - Orchesia micans; b - Pseudolycus haemorrhoidalis; c - Meryx rugosa; c Pytho niger. Abbreviations: hy - hypopharynx, o52 - origin of M. tentoriopharyngalis, pta - posterior tentorial arm, tb - tentorial bridge, $15-$ M. craniocardinalis, $17-$ M. tentoriocardinalis, $18-$ M. tentoriostipitalis, $19-$ M. craniolacinialis, $41-$ M. frontohypopharyngalis, $42-$ M. tentoriohypopharyngalis medialis.

gitudinal sclerotisations and median area between them densely covered with microtrichiae above dorsal surface of molae. Posterior epipharynx forms a preoral chamber together with the mandibular bases and the hypopharynx, and a very narrow prepharyngeal tube by fusion with the lateral margin of the posterior hypopharynx.

Musculature (Fig. 5b): M 43: M. clypeopalatalis, poorly developed, two narrow bundles, O: anterior to $\mathrm{M} \mathrm{45,} \mathrm{I:}$ posterior prepharyngeal roof. Transverse muscles only present at posterior margin of prepharyngeal tube.

2.10. Hypopharynx (Figs 5b, 6b). Anterior part posteriorly adjacent with dorsal premental surface, semimembranous, pad-like, densely covered with microtrichiae, separated from posterior part by strongly sclerotised transverse bar. Posterior hypopharynx forms ventral wall of preoral chamber and prepharyngeal tube.

$\begin{array}{lllll}\text { Musculature (Fig. 5b): } & \text { M 41: } & \text { M. }\end{array}$ frontohypopharyngalis, O: posterior frons, lateral to $\mathrm{M} 9$, I: posterolaterally on prepharynx by means of a very strong tendon; M 42m: M. tentoriohypopharyngalis medialis, O: tentorial bridge, I: posteromedially on ventral hypopharyngeal wall; M 421: M. tentoriohypopharyngalis lateralis: absent.
2.11. Pharynx (Fig. 5b). Narrow, with distinct dorsolateral, lateral and ventrolateral folds. Posterior pharynx forms loop between posterior cerebrum and suboesophageal complex (Fig. 5b).

Musculature (Fig. 5b): M 45: M. frontobuccalis anterior, $\mathrm{O}$ : frons, between anterior bundle of M 46 and posterior bundle of $\mathrm{M} \mathrm{43}$, I: dorsally on anatomical mouth; M 46: M. frontobuccalis posterior, series of very thin bundles, O: posterior frons, lateral to $\mathrm{M}$. frontoepipharyngalis, I: dorsolaterally on pharynx; M 51: M. verticopharyngalis: absent; M 52: $\mathrm{M}$. tentoriopharyngalis, two groups of muscles, M 52a, series of very thin pairs of bundles, O: ventrolaterally from postoccipital ridge, I: on ventrolateral and ventral folds of posterior pharynx, below attachment of bundles of M 46; M 52b, series of well developed bundles, O: gular ridges, I: ventrolateral and ventral folds of pharynx. Ring musculature well developed (Fig. 5b).

2.12. Cerebrum and suboesophageal complex (Fig. 5b). Comparatively small in relation to size of head capsule. Posterior part of cerebrum extends into anterior prothoracic region. Submentum almost completely located in prothorax. 

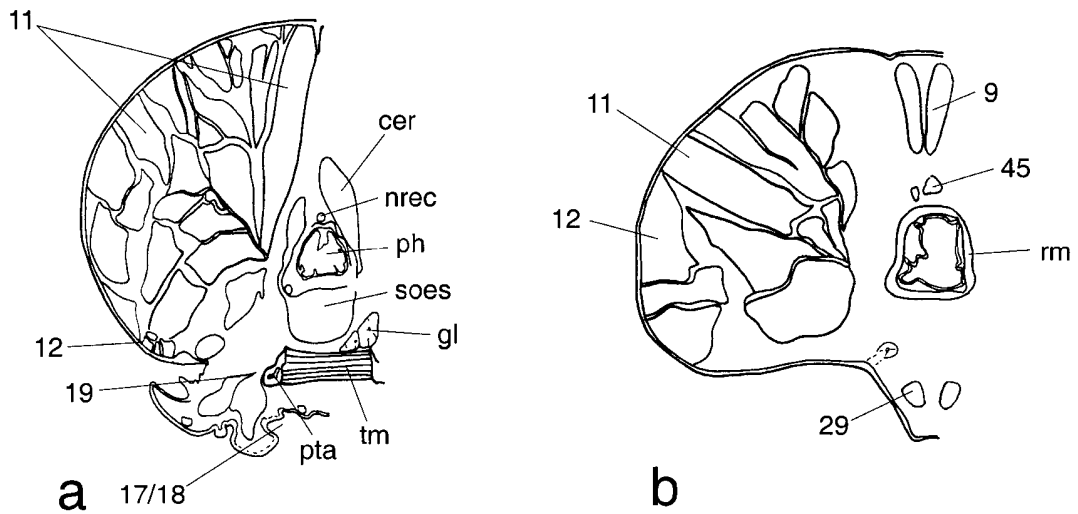

b
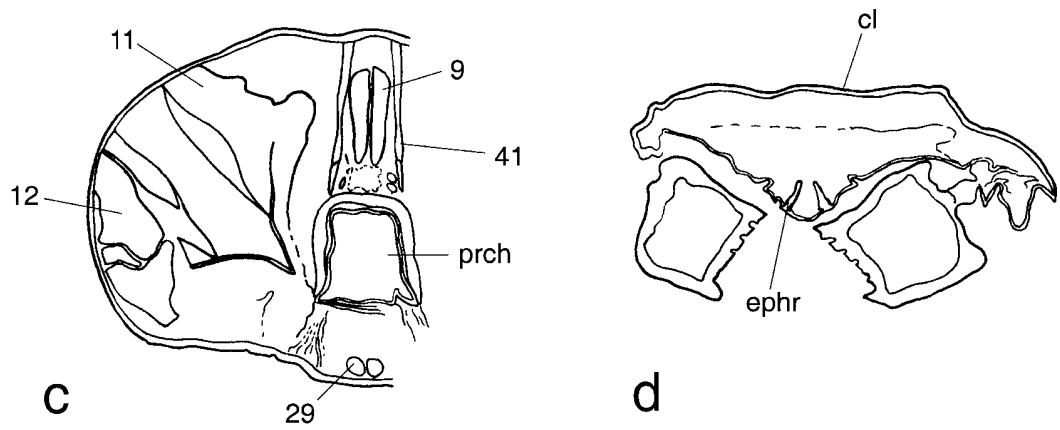

d

Figs 8a-b: Cross sections, Orchesia micans, head. a - posterior head region; b - anterior pharyngeal region; c - anatomical mouth region; $\mathrm{d}$ - epipharyngeal region. Abbreviations: cer - cerebrum, cl - clypeus, ephr - epipharyngeal ridge, gl - tube-like salivary glands, nrec - nervus recurrens, ph - pharynx, prch - preoral chamber, pta - posterior tentorial arm, rm - ring muscle, soes - suboesophageal complex, $\mathrm{tm}$ - transverse gular muscle, $9-\mathrm{M}$. frontoepipharyngalis, $11-\mathrm{M}$. craniomandibularis internus, $12-\mathrm{M}$. craniomandibularis externus, $17-\mathrm{M}$. tentoriocardinalis, $18-\mathrm{M}$. tentoriostipitalis, $19-\mathrm{M}$. craniolacinialis, $29-$ M. tentoriopraementalis inferior, $41-\mathrm{M}$. frontohypopharyngalis, $43-\mathrm{M}$. clypeopalatalis, $45-\mathrm{M}$. frontobuccalis anterior.

2.13. Glands (Fig. 5b). A pair of tube-like glands originates in the prothorax and opens between the bases of mentum and maxillae.

2.14. Fat body (Fig. 5b). Massive fat body present in anterior prothorax (Fig. 5b), but absent from head capsule.

2.15. Prothorax (Figs 1b, 2b, 10b). Slightly longer than following thoracic segments. All parts cream-white or testaceous, lightly sclerotised except for anterodorsal semimembranous collar and lateral marginal area of pronotum. Pronotum extending to lateral side of prothorax. Unsclerotised lateral part anteriorly adjacent with anterior transverse sternal plate and posteriorly with epimeral part of pleura. Anterior pronotum moderately arched, posterior part transformed into a distinctly bulging, transverse ampulla with asperities. Ventral side with extensive, transverse, bulging anterior plate, probably representing a fused presternum + cervicosternum, medially not distinctly separated from basisternal plate, which is inserted between the coxae. Indistinct, rounded line separates basisternum from the short, transverse sternellum, which is anteromedially inserted between the posterior part of the coxae. Pleural suture and episternal part of pleura not exposed, covered by unsclerotised lateral part of pronotum and lateral part of anterior sternal plate. Epimeral part connected with sternellum posteriorly. Coxae widely separated, broad and oblique. Trochanter well developed, appearing fused with femur mesally. Femur longer than other leg segments, slightly extended distally. Tibia conical. Tarsungulus well developed, with two setae (Figs $2 b$, 10b). Setation of other parts as shown in Figs $1 b, 2 b$ and $10 \mathrm{~b}$.

2.16. Mesothorax (Figs 1b, 2b). Mesonotum with paired anterior ampullae with asperities. Posterior part moderately arched. Basisternum large, laterally adjacent with mesepimeron, bulging, with indistinctly delimited triangular anteromedian area. Laterotergite with membranous, setiferous protuberance (Fig. 2b). Pleural suture, episternum and epimeron exposed. Coxae widely separated. Legs similar to prothorax. Spiracle indistinct, located on small elevation above posterodorsal margin of prothoracic epimeral area. Coxae widely separated. Legs similar to prolegs.

2.17. Metathorax (Fig. 1b). Similar to mesothorax (Fig. 1b).

2.18. Abdominal segments I-VII (Fig. 1b). Abdomen very slightly narrowing posteriorly. Distribution of setae as shown in Figs $1 \mathrm{~b}$ and $11 \mathrm{~b}$. Segments II-V longer and broader than I and terminal segments, segment III longer than II, IV and V. Tergites II and III with paired ampullae with asperities slightly smaller than those of meso- and metathorax. Unsclerotised pleural areas with membranous, setiferous protuberances, smaller and more clearly defined on anterior segments, broader on posterior segments. Sternites lightly sclerotised, separated from 

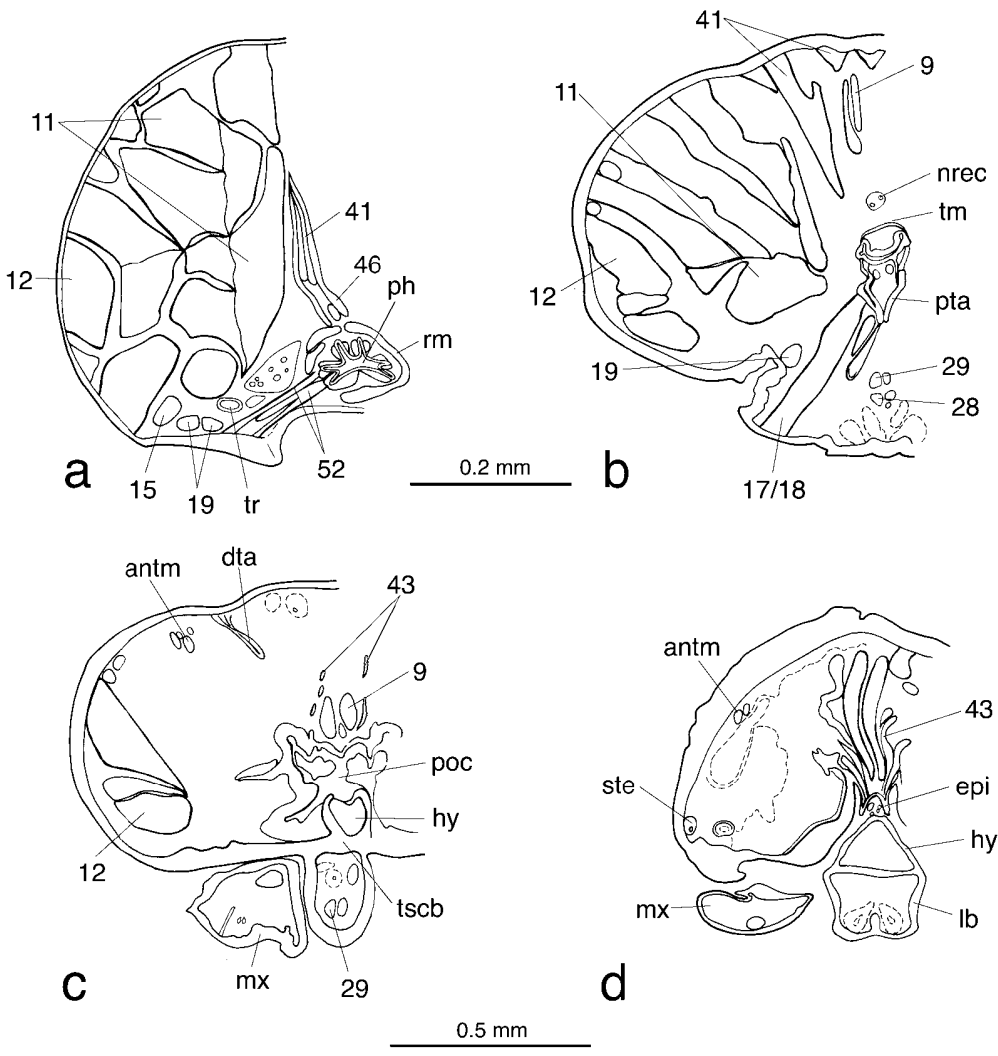

Figs 9a-d: Cross sections. a-b - Curtimorda sp., head; a - posterior pharyngeal region; $\mathrm{b}-$ cibarial region; $\mathrm{c}-\mathrm{d}-$ Mycetoma sp., head; $\mathrm{c}$ - posterior prepharyngeal region; $\mathrm{d}$ - cibarial region. Abbreviations: antm - antennal muscles, dta - dorsal tentorial arms, epi - epipharynx, hy - hypopharynx, $\mathrm{lb}$ - labium, $\mathrm{mx}$ - maxilla, nrec - nervus recurrens, $\mathrm{ph}$ - pharynx, poc - preoral cavity between mandibular bases, pta - posterior tentorial arm, $\mathrm{rm}$ - ring muscle, ste - stemma, $\mathrm{tm}$ - transverse muscle, $\operatorname{tr}-\operatorname{trachea}$, tscb - transverse sclerotised bar, $9-\mathrm{M}$. frontoepipharyngalis, $11-\mathrm{M}$. craniomandibularis internus, $12-\mathrm{M}$. craniomandibularis externus, $15-$ M. craniocardinalis, 17 - M. tentoriocardinalis, $18-$ M. tentoriostipitalis, $19-$ M. craniolacinialis, $28-$ M. submentopraementalis, 29 - M. tentoriopraementalis inferior, 41 - M. frontohypopharyngalis, 43 - M. clypeopalatalis, $52-$ M. tentoriopharyngalis.

pleural area by distinct rim, with very indistinct setiferous lateral protuberances, otherwise unmodified.

2.19. Abdominal segment VIII (Figs 1b, 11b). Tergum with rounded posterior margin, narrower than anterior segments.

2.20. Abdominal segments IX and $X$ (Figs 1b, 11b). Segment IX round in cross section and with rounded posterior margin, without urogomphi. Sternite IX much shorter than preceeding sternites. Segment X posteroventrally directed, with separate dorsal tergal part and membranous ventral part.

2.21. Spiracles (Fig. 2b). Annular-biforous, with short accessory tubes.

\section{Meryx rugosa Latreille, 1807 (Ulodidae)}

3.1. General appearance (Fig. 1c). Length of last instar larvae $10.2-14.4 \mathrm{~mm}(\mathrm{n}=4)$. Head shiny and dark brown. Legs well developed. Body elongate and slender, parallel-sided, sub-cylindrical, with groups of very long setae. Abdomen about 2.5 times longer than thorax. Tergites distinct. Segment IX strongly sclerotised, dorsally covered with tubercles. Urogomphi distinct, hook-shaped.

3.2. Head capsule, external features (Figs 2c, 3c, 4c, 5c). Head protracted, cervical membrane more or less broadly exposed dorsally, wedge-shaped in lateral view, slightly rounded laterally. Ventral side horizontal. Most setae very long, distributed as shown in Figs 2c, 3c and 4c. Antennae inserted posterior to dorsal mandibular articulation, with prominent membranous articulation area. Five stemmata arranged in two vertical rows of three and two respectively (Fig. 2c). Labrum moveable, connected to clypeus by a membranous fold (Figs 3c, 5c). Clypeus short but very distinctly separated from frons, with transparent anterior margin. Anterior tentorial grooves not recognisable. Frons broad anteriorly, narrowed posteriorly. Frontal suture (= frontal arms) lyriform, with transverse anterior part ending posterior to antennal articulation. Coronal suture short. Median endocarina present, coincident with coronal suture. Hypostomal rods present but scarcely visible externally, internally represented by well developed ridge along lateral margin of maxillary fossae. Posteriorly very indistinct, slightly converging. Epicranial ridge absent. Maxillary grooves deep, anteriorly closed by a semitransparent internal supramaxillary bridge. Gula well developed and sclerotised, trapezoid, posteriorly diverging (Fig. 4c).

3.3. Internal skeletal structures (Figs 5c, 7c). Posteriorly diverging, well-developed gular ridges posteriorly continuous with postoccipital ridge, with strong internal sclerotisation. Posterior tentorial arms strongly developed, arising posterior to maxillary fossa, with dis- 


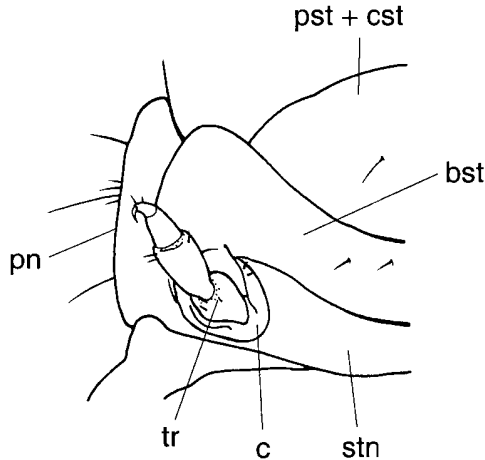

a $0.5 \mathrm{~mm}$

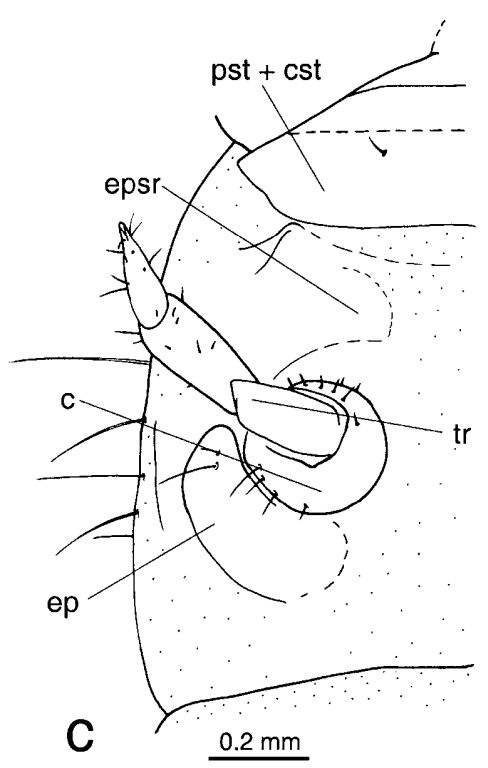

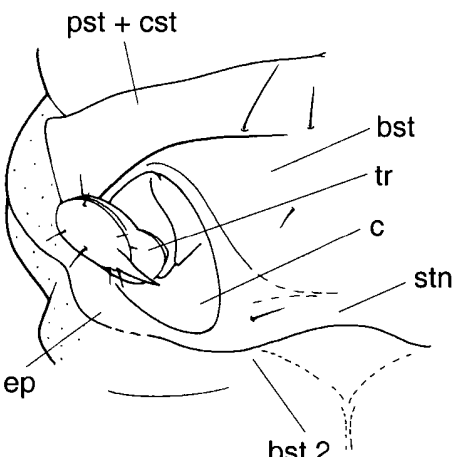

b $0.5 \mathrm{~mm}$

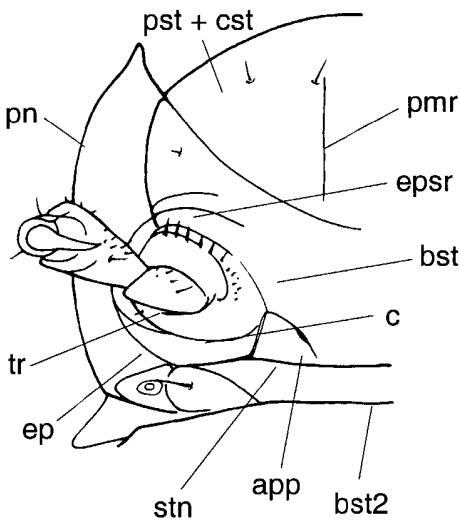

d $3 \mathrm{~mm}$

Figs 10a-d: Prothorax, ventral view. a - Orchesia micans; $\mathrm{b}$ - Pseudolycus sp.; c - Meryx rugosa; $\mathrm{d}-$ Pytho niger. Abbreviations: app - apophyseal pits, bst/2 - basisternum/2, c - coxa, ep - epimeron (epimeral area), epsr - episternal area, pmr - paramedian ridges, $\mathrm{pn}-$ pronotum, $\mathrm{pst}+\mathrm{cst}-$ presternum + cervicosternum, stn - sternellum, $\mathrm{tr}-$ trochanter.

tinct posteriorly directed process, converging anteriorly, contiguous or fused to form a horizontal plate for attachment of Mm. tentoriocardinalis and - stipitalis. Dorsal arms very flat and unsclerotised, dorsally attached to head capsule by means of fibrillar structures. Tentorial bridge and anterior arms absent.

3.4. Labrum (Figs 3c, 5c). Fairly narrow, rounded laterally and convex anteriorly, connected with clypeus by a membranous fold. Lateral edge with a row of strong, curved spines. Ventral side convex, with strongly sclerotised internal transverse bar.

Musculature (Figs 5c, 6c): M 7: M. labroepipharyngalis, absent; $M$ 9: M. frontoepipharyngalis: strong muscle, O: median endocarina, I: paramedian ridges of epipharynx.

3.5. Antenna (Figs 2c, 3c, 4c). Short, 3-segmented, ventrally directed. Antennomere I short and broad, antennomere II slightly widening towards apex, distinctly longer than broad, antennomere III slender, parallel-sided, rounded apically, with a group of sensorial setae.
Musculature (Fig. 6c): Mm 1, 2, 4: M. tentorioscapalis anterior, posterior, medialis, $\mathrm{O}$ : dorsal wall of head capsule, I: anteroventrally, posteriorly, and dorsally on the base of antennomere I.

3.6. Mandible (Figs 5c, 6c). Slightly asymmetric, with slender apical tooth, small subapical tooth, and a strongly sclerotised, atypical, asymmetric molar area without asperities. Molar area of each mandible with two cutting edges which fit into each other. Prostheca absent.

Musculature (Figs 5c, 6c): M 11: M. craniomandibularis internus, largest muscle of the head, O: extensive parts of the dorsolateral and ventrolateral areas of the head capsule, I: adductor tendon; M 12: M. craniomandibularis externus, O: lateral wall of head capsule, I: abductor tendon.

3.7. Maxilla (Figs 4c, 7c). Inserted in a well developed, fossa maxillaris, which is dorsally closed by a transparent transverse bar. Articulatory area not pad-like, small lateral part sclerotised, mesal part semimembranous. Cardo transverse, connected with stipes by a hinge, divided by an internal ridge. Mala broad, apically cleft, with a dense fringe of strong setae along anterior and mesal margin 

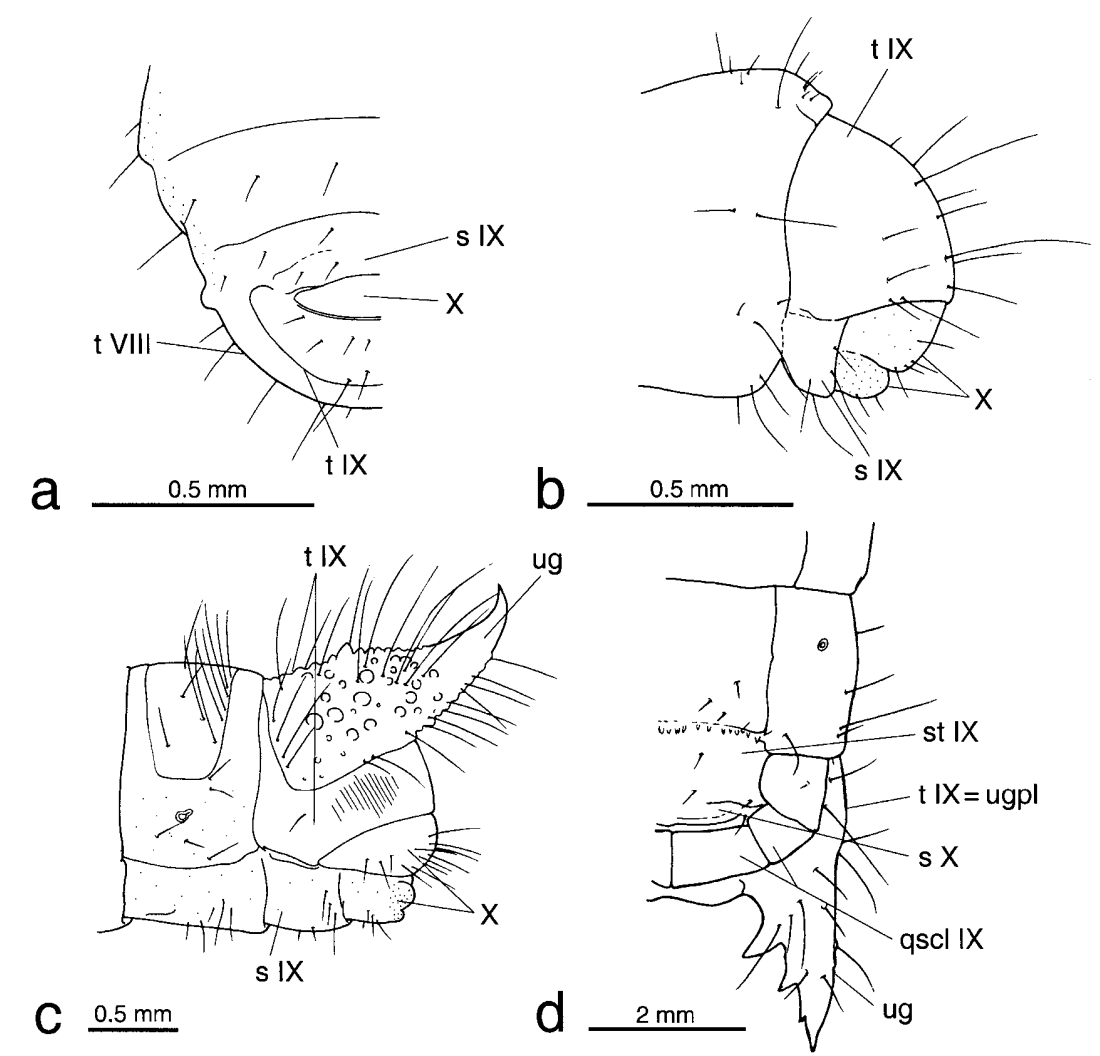

Figs 11a-d: Terminal abdominal segments. a - Orchesia micans, ventral view; b - Pseudolycus sp., lateral view; c - Meryx rugosa, lateral view; $\mathrm{d}$ - Pytho niger, ventral view. Abbreviations: qscl IX - quadrangular sclerites forming sternite IX, sIX/X sternum IX/X, t VIII/IX - tergum VIII/IX, ug - urogomphi, ugpl - urogomphal plate, X - segment X.

and a small tooth-like apicomesal projection (Fig. 7c). Mesally directed setae functionally associated with strongly developed setae of premento-hypopharyngeal surface (see below). Palp 3-segmented, moderately long. Distinct palpifer not developed. Palpomeres I-II almost as broad as long, apical palpomere slightly longer and apically rounded.

Musculature (Fig. 7c): M 15: M. craniocardinalis, absent; Mm 17/18: Mm. tentoriocardinalis and - stipitalis, several strong bundles, O: posterior tentorial arm, I: ventral surface of cardo and stipes and mesal stipital edge; $M$ 19: M. craniolacinialis, two parallel bundles, O: ventrolaterally from posterior margin of head capsule, I: base of mala; Mm 22/23: M. stipitopalpalis externus and internus, represented by a single bundle, $\mathrm{O}$ : ventral surface of stipes, I: base of maxillary palp. A muscle with unclear homology originates from the lateral stipital wall and is attached to the dorsal wall of the anterior part of the stipes.

3.8. Labium (Figs 4c, 5c, 7c). Submentum distinctly separated from gula, elongate and narrowed between maxillary articulatory areas. Mentum parallel-sided, distinctly longer than broad, with pair of long, ventrally directed setae. Prementum small, with fairly short, 2-segmented palps. Ligula sclerotised and conspicuous, about as long as palps, with a subapical pair of setae, an apical pair of setae, and a group of anteriorly directed spines.
Musculature (Figs 5c, 7c): M 28: M. submentopraementalis, O: medially on posterior margin of submentum, I: ventromedially on posterior premental margin; M 29: $\mathrm{M}$. tentoriopraementalis inferior, $\mathrm{O}$ : posterior margin of submentum close to M 28a, I: ventromedially on posterior mental margin; M 30: M. tentoriopraementalis superior, absent; M 34: M. praementopalpalis externus, absent; M. submentogularis transversalis, absent.

It is possible that the muscle here interpreted as M 29 is a subcomponent of M 28.

3.9. Epipharynx (Figs 5c, 6c). Anterior epipharynx slightly convex, with shallow median edge and very strong paramedian sclerotised longitudinal rods. Anteriormost part, i.e. ventral side of labrum, with longitudinal fields of internally directed microtrichiae. Fine microtrichiae also present between paramedian rods. Posterior part forming a very short preoral chamber together with the mandibular bases and the hypopharynx, and a moderately long prepharyngeal tube with the posterior hypopharynx. Prepharynx with distinct dorsolateral and ventrolateral folds, and an almost quadrangular shape in cross section.

Musculature (Fig. 5c): M 43: M. clypeopalatalis, composed of several moderately sized bundles, $\mathrm{O}$ : anterolateral frons, I: on dorsolateral fold of prepharyngeal roof.

Transverse muscles are present between the anterior components of M 43 and between M 43 and M 45 .

3.10. Hypopharynx (Figs 5c, 7c). Anterior part not separated from dorsal side of elongate ligula and premen- 
tum. Surface with strong, dorsally directed setae and short spines. Lateral walls of labio-hypopharyngeal complex connected by strong internal bar, which is posteriorly interrupted and connected by fibrillar structures. Posterior margin of anterior hypopharynx demarcated by transverse bar. Posterior hypopharynx fused with epipharynx laterally, forming a wide prepharyngeal tube, which is almost quadrangular in cross section.

Musculature (Fig. 5c): M 41: M. frontohypopharyngalis, O: central area of frons, between M 9 and M 11, I: on a strong lateral hypopharyngeal apodeme at the hind margin of the prepharyngeal tube; $\mathrm{M} 42 \mathrm{~m}$ : $\mathrm{M}$. tentoriohypopharyngalis medialis, a pair of thin bundles, $\mathrm{O}$ : not clearly identified, probably from apical part of posterior tentorial arms, I: medially on the ventral wall of the prepharyngeal tube; M 421: M. tentoriohypopharyngalis lateralis, thin muscle fibres, O: proximal part of dorsal tentorial arm, I: laterally on hind margin of prepharyngeal tube.

3.11. Pharynx (Fig. 5c). Fairly wide, almost quadrangular. Dorsolateral, lateral and ventrolateral folds of posterior pharynx indistinct, more distinct towards anatomical mouth. Anterior pharynx continuous with prepharyngeal tube. Postcerebral part of pharynx forming a loop.

Musculature (Fig. 5c): M 45: M. frontobuccalis anterior, O: frons, anterior to $\mathrm{M} \mathrm{41}$; I: anatomical mouth; M 46: M. frontobuccalis posterior, a series of thin bundles, O: posterior head capsule, lateral to coronal suture, I: dorsolaterally and dorsally on pharynx; M 51: M. verticopharyngalis: absent; $\mathrm{M}$ 52: $\mathrm{M}$. tentoriopharyngalis, divided into 3 subcomponents, each of them composed of several thin bundles, O: postoccipital ridge, posterior gular ridge and posteriorly directed process of posterior tentorial arm, I: ventrolaterally and ventrally on posterior pharynx.

Well developed ring muscles present over the whole length of the pharynx (Fig. 5c)

3.12. Cerebrum and suboesophageal complex (Fig. 5c). Cerebrum located in the posterior head region, asymmetric. Suboesophageal complex laterally enclosed by gular ridges.

3.13. Glands (Fig. 5c). A pair of tube-like glands originating in the prothorax. The precise location of the opening in the preoral area could not be identified with the available microtome sections.

3.14. Oesophagus. Posterior oesophagus modified as proventriculus, with moderately thick cuticle, ventral, lateral and dorsal folds and a well developed layer of thin ring muscles.

3.15. Fat body. Present in the posteriormost part of the head.

3.16. Prothorax (Figs 1c, 2c, 10c). Slightly longer than following thoracic segments and equally broad (Fig. 1c). Tergite distinctly sclerotised and dark brown in colour, medially divided by a very thin suture, laterally extending to pleural area, almost saddle-like. Dorsal side and anterior and posterior margins with very long setae (Figs 1c, 2c). Areas anteriorly and posteriorly adjacent with tergum sclerotised but unpigmented, with longitudinal parallel striae. Laterotergite broad, largely semimembranous, but with indistinct posterior sclerotised area with a long seta. Anteromedian part of sternum probably composed of the presternum and cervicosternum, reaching gula anteriorly, slightly sclerotised and bulging, with pair of ventrally directed setae (Fig. 10c). Other parts undivided, unsclerotised and unpigmented, not clearly separated from pleural parts. Pleural suture above coxal cavity distinct, not completely dividing lightly sclerotised episternum and epimeron. Legs distinctly separated, 5-segmented, composed of conical coxa with several strong spines anterodistally, well developed trochanter, femur, tibiotarsus, and a strong pretarsal claw with two setae (Figs 2c, 10c).

3.17. Mesothorax (Figs 1c, 2c). Shorter than prothorax. Tergum sclerotised and dark brown, with sharp anterior edge but without asperities, sligthly narrower than protergum. Median suture, adjacent sclerotised, unpigmented areas and setation similar to prothorax. Upper parts of pleura semimembranous. Episternum and epimeron separated by short pleural suture, very lightly sclerotised and pigmented. Anteromedian part of sternal area distinctly bulging, main part without clearly separated areas, largely unsclerotised. Annularbiforous stigma located on small anterolateral pleural elevation close to intersegmental border. Legs similar to prothoracic legs, slightly longer.

3.18. Metathorax (Fig. 1c). Very similar to mesothorax in shape and extension, without stigma.

3.19. Abdominal segments I-VII (Fig. 1c). Abdomen parallel-sided and elongate. Segments I-VII similar to meso- and metathorax, with well developed, sclerotised tergites with median suture and sharp anterior edge, without asperities. Setation similar to meso- and metatergite. Pleurae semimembranous. Sternites lightly sclerotised, testaceous.

3.20. Abdominal segment VIII (Fig. 11c). Tergum slightly longer and darker, with very strongly pronounced anterior edge, otherwise similar to segments I-VII.

3.21. Abdominal segments $I X$ and $X$ (Fig. 11c). Tergum IX with strongly sclerotised, very dark dorsal part, with numerous large tubercles and long setae (Fig. 11c). Lateral parts and almost vertical posterior part lightly sclerotised and testaceous. Sternum IX simple, shorter than preceeding sterna. Well developed urogomphi arise from dorsal part of tergum, distinctly curved upwards. Apical part largely smooth, without accessory process. Segment X posteriorly directed, with well developed, lightly sclerotised tergal part with long, posteriorly directed setae, and a largely membranous sternal part with few setae and posteriorly directed, papilla-like structures.

3.22. Spiracles (Fig. 2c). Annular-biforous, with short accessory tubes.

\section{Pytho sp. (Pythidae)}

4.1. General appearance (Fig. 1d). Strongly flattened, subparallel, slightly widening towards abdominal apex. Length of last instar larvae $23-25 \mathrm{~mm}(\mathrm{n}=4)$. Colour creamy white except for strongly sclerotised parts of head capsule, mouth parts and segment IX. Surface smooth, with sparse vestiture of thin setae. Legs well developed. 
Abdomen more than three times longer than thorax. Tergite IX plate like, extending to ventral side, with distinct urogomphi.

4.2. Head capsule, external features (Figs $2 \mathrm{~d}, 3 \mathrm{~d}, \mathbf{4 d}$, 5d). Head slightly retracted, prognathous, with dorsal side almost horizontal, laterally rounded, greatest width at posterior third of head capsule. Setation as shown in Figs 2d, $3 \mathrm{~d}$ and $4 \mathrm{~d}$. Antennae inserted on moderately protruding, sclerotised elevation anterior to stemmata. Five stemmata present, arranged in a vertical anterior row of three and a vertical posterior row of two. Labrum moveable, connected to clypeus by a membranous fold (Fig. 5d). Clypeus fairly long, with broad transparent anterior margin, fused with frons posteriorly. Frontal suture (= frontal arms) lyriform, transverse anteriorly, with distinct anterolateral section reaching posterior margin of antennal articulation area. Frons broad anteriorly, almost reaching posterior margin of head capsule posteriorly, posterior margin slightly concave. Coronal suture present but very short, covered by anterior margin of prothorax. Dorsal endocarina absent. Hypostomal rods absent. Epicranial ridges distinct. Maxillary grooves deep. Gula broad, moderately long, slightly convergent anteriorly, fused with submentum, laterally delimited by very distinct gular suture. Posterior tentorial grooves posterior to maxillary groove fissure-shaped, continuous with gular ridge. Posterior part of gula covered by anteromedian prosternal plate. Posteriormost part of ventral side of head closed by broad semimembranous area with low lateral ridges and a median postgular sclerotisation. Dorsal membranous fold connecting head and thorax with paired transverse cervical sclerites.

4.3. Internal skeletal structures (Figs 5d, 7d). Posteriorly diverging, very low ridges delimiting semimembranous postgular area, posteriorly continuous with postoccipital ridge. Gular ridges continuous with base of tentorium. Posterior arms strongly developed, arise posterior to maxillary fossa, converging anteriorly. Dorsal arms very flat and unsclerotised, dorsally attached to head capsule by fibrillae. Tentorial bridge well developed, fairly broad. Anterior arms absent.

4.4. Labrum (Figs 3d, 5d, 6d). Fairly narrow, rounded laterally and convex anteriorly. Setae as shown in Fig. 3d.

Musculature (Figs 5d, 6d): M 7: M. labroepipharyngalis: absent; M 9: frontoepipharyngalis, well developed muscle, O: posterior margin of frons, I: paramedian ridges of epipharynx.

4.5. Antenna (Figs 3d, 4d, 6d). Fairly long, about $1 / 3$ of maximum head width, 3-segmented. Antennomere I and II elongate, about three times longer than wide. Sensorial appendage of antennomere II small and conical, inserted ventrally on apical membranous area. Antennomere III slightly shorter than I and II and slender, with apical group of fairly long sensillae.

Musculature (Fig. 6d): Mm 1, 2, 4: M. tentorioscapalis anterior, posterior, medialis, $\mathrm{O}$ : dorsal wall of head capsule, lateral to attachment of dorsal tentorial arms, I: anteroventrally, posteriorly, and dorsally on the base of antennomere I.
4.6. Mandible (Figs 5d, 6d). Distinctly asymmetric. Broad at base, with slender distal part with two apices and 2 small subapical teeth. Molae present, asymmetric, with transverse ridges. Left mandible with prominent molar tooth.

Musculature (Figs 5d): M 11: M. craniomandibularis internus, largest muscle of the head, O: extensive parts of the dorsal, dorsolateral and ventrolateral areas of the head capsule, I: adductor tendon; M 12: M. craniomandibularis externus, O: lateral wall of head capsule, I: abductor tendon.

4.7. Maxilla (Figs 4d, 7d). Articulatory area pad-like. Cardo transverse, connected with stipes by a hinge, divided by an internal ridge. Mala broad, apicolaterally rounded, very shallowly cleft anteromesally, with a mesally directed protuberance with three distinct teeth. Anterolateral margin with a group of longer anteriorly directed setae, anteromesal margin and mesal margin proximal to protuberance with stronger and shorter mesally directed setae. Palp 3-segmented and fairly short. Distinct palpifer not developed. Palpomeres stout, about twice as long as broad. Apical palpomere with a dense apical field of minute sensillae.

Musculature (Figs 5d, 7d): M 15: M. craniocardinalis, an extremely thin bundle between the two subcomponents of M 19, O: posterior to M 19, ventrolaterally on posterior margin of head capsule, I: laterally attached to cardinal base by means of a thin tendon; Mm 17/18: Mm. tentoriocardinalis and - stipitalis, several strong bundles, $O$ : posterior tentorial arm, I: ventral surface of cardo and stipes and mesal stipital edge; M 19: M. craniolacinialis, two parallel bundles, $\mathrm{O}$ : ventrolaterally from posterior part of head capsule, between bundles of M 11, I: base of mala; Mm 22/23: M. stipitopalpalis externus and internus, represented by two parallel bundles, $\mathrm{O}$ : ventral surface of stipes, I: laterally on base of maxillary palp.

4.8. Labium (Figs 4d, 5d). Submentum trapezoidal, anteriorly narrowing, posteriorly fused with gula, border between both areas demarcated by a distinct edge. Mentum widened anteriorly, with a pair of ventrally directed setae. Proximolateral margin covered by pad-like maxillary articulatory area. Prementum broad and short, with short, 2-segmented palps. Both palpomeres about equally long. Ligula sclerotised and well developed, extending anteriorly beyond apex of palps, with pair of anteriorly directed setae and a very dense apical field of microtrichiae.

Musculature (Fig. 5d): M 28: M. submentopraementalis, O: posterior margin of submentum, I: ventromedially on posterior premental margin; $M$ 29: $\mathrm{M}$. tentoriopraementalis inferior, $\mathrm{O}$ : mesally from base of posterior tentorial arm, I: together with M 28.

A very strongly developed transverse muscle connects the lateral walls of the mentum.

4.9. Epipharynx (Figs 5d, 6d, 7d). Anterior part moderately convex, with indistinct median ridge. Median part densely covered with very short, mesally directed microtrichiae. Intermediate epipharyngeal section flat, forming preoral chamber together with mandibular bases and 
hypopharynx. Posterior part laterally fused with hypopharynx, forming broad and flat, moderately long prepharyngeal tube.

Musculature (Figs 5d, 7d): M 43: M. clypeopalatalis, modestly developed, composed of two bundles; O: frons, anterior to M 45, I: on dorsolateral folds of prepharyngeal roof.

Transverse muscles are present between the bundles of M 43 and M 45.

4.10. Hypopharynx (Figs 5d, 7d). Anterior part posteriorly adjacent to dorsal side of ligula, with distinct lateral edges with very dense longitudinal combs of hairs and a convexity between them. Dense transverse brush of stronger hairs present on transverse bar anterior to opening of preoral chamber (= transverse sclerome), left side of sclerome with molar-like modification. Posterior part of hypopharynx forming floor of preoral chamber or prepharyngeal tube, respectively, devoid of hairs or microtrichiae.

Musculature (Figs 5d, 7d): M 41: M. frontohypopharyngalis, $\mathrm{O}$ : posterior frons, anterior to origin of $\mathrm{M} 9$, I: with a strong apodeme at the hind margin of the prepharyngeal tube; $\mathrm{M}$ 42: $\mathrm{M}$. tentoriohypopharyngalis medialis, a strong muscle, $\mathrm{O}$ : tentorial bridge, I: medially on the ventral wall of the prepharyngeal tube.

4.11. Pharynx (Fig. 5d). Fairly narrow, with deep folds and very narrow lumen. Anterior pharynx continuous with prepharyngeal tube.

Musculature (Fig. 5d): M 45: M. frontobuccalis anterior, $\mathrm{O}$ : anterior frons; I: dorsally on anatomical mouth, between tendons of $\mathrm{M} \mathrm{41;} \mathrm{M} \mathrm{46:} \mathrm{M}$. frontobuccalis posterior, a series of thin bundles, $\mathrm{O}$ : posterior frons, lateral to M 9, I: dorsolaterally and dorsally on pharynx; M 51: M. verticopharyngalis, absent; M 52: M. tentoriopharyngalis, a series of thin muscles, $\mathrm{O}$ : gular ridge and posterior tentorial arm, I: ventrolaterally and ventrally on posterior pharynx. Well developed ring musculature present over the whole length of the pharynx (Fig. 5d).

4.12. Cerebrum and suboesophageal complex (Fig. 5d). Cerebrum and suboesophageal complex located in posterior head region, relatively small in relation to head size. Suboesophageal complex reaching tentorial bridge anteriorly.

4.13. Glands. A pair of tube-like glands originating in the prothorax. The precise location of the distal opening could not be identified.

4.14. Fat body. Voluminous tube-like compartments of the fat body present in the posterior part of the head.

4.15. Prothorax (Figs 1d, 2d, 10d). Longer than following thoracic segments and equally broad (Fig. 1d). Setation as shown in Figs 1d, 2d and 10d. Tergite flat, sclerotised and shiny, but almost completely unpigmented like other parts of body segments, separated into two halves by median suture, with distinct lateral edge and broad, sclerotised inflected part. Large, flat anteromedian plate of sternum probably composed of the presternum and cervicosternum, covering posterior part of gula anteriorly, incompletely divided by a pair of paramedian ridges, with two pairs of ventrally directed setae. Basi- sternum large, fused with episternal area anterior to coxae, with distinct sternal apophyseal pits posteriorly. Small, paired, triangular sclerites between apophyses and posteromesal coxal margin possibly represent a part of the sternellum, separated from epimeral area by a suture. Pleural suture above coxal cavity distinct, clearly dividing episternal and epimeral areas (Fig. 2d). Legs broadly separated, fairly long, 5-segmented, composed of conical coxa with anterior row of spines, well developed trochanter, femur, tibiotarsus, and a strong pretarsal claw (Figs 2d, 10d) with two setae.

4.16. Mesothorax (Figs 1d, 2d). Shorter than prothorax. Tergum with median suture and medially interrupted transverse ridge shortly posterior to anterior margin. Lateral edge less distinct, inflected part of tergum moderately broad. Exposed part of pleural suture short. Intersternite fairly broad, with separate lateral piece. Sternum undivided. Spiracle located on elevation between posterior inflected margin of protergum and anterior inflected margin of mesotergum, annular with crenulate margin on one side. Legs similar to prothoracic legs.

4.17. Metathorax (Fig. 1d). Shorter than mesothorax, otherwise similar. Without stigma. Legs similar to prothoracic legs, slightly longer.

4.18. Abdominal segments I-VII (Fig. 1d). Abdomen subparallel, elongate and strongly flattened. Segments very slightly rounded laterally, with lateral groups of long setae. Other setae as shown in Fig. 1d. Segment I shorter than following segments. All segments with distinct anterior ridges (= parabasal ridges sensu Pollock, 1991) with median processes [see Fig. 1d (indicated by arrow) and Pollock, 1991]. Segments II-VII with short, paramedian, longitudinal ridges. Tergites not separated from pleural area. Flat and sclerotised sterna separated from lateral part of segments by distinct longitudinal fold. Spiracles close to anterior margin of segments.

4.19. Abdominal segment VIII (Figs 1d, 11d). Slightly longer than segment VII, with almost straight lateral margin. Paramedian ridges very short. Sternite VIII and IX indistinctly separated medially.

4.20. Abdominal segments $I X$ and $X$ (Figs 1d, 11d). Segment IX strongly sclerotised, with a semicircular row of eight large tubercles on dorsal side and strong, fixed urogomphi with three mesally directed projections. Pit between urogomphi broad, dark and strongly sclerotised. Tergite extending ventrally to form entire terminal segment (= urogomphal plate), with an arch of six quadrangular sclerites around sternite IX and segment $\mathrm{X}$. Quadrangular sternite IX with an anterior row of 20-21 subequal asperities, indistinctly separated posteriorly from strongly reduced, ventrally directed sternum X.

\subsection{Spiracles (Fig. 2d). Annular.}

\section{CHARACTERS USED IN THE ANALYSIS}

1. Body shape: (0) subcylindrical to slightly flattened; (1) strongly flattened. A strongly flattened body is characteristic for larvae of Prostomidae, Mycteridae, Boridae, Pythidae (Figs 1d, 2d; part., coded as 0\&1) and Pyrochroidae (Costa et al., 1988; Lawrence, 1991; Lawrence et al., 1999; Pollock et al., 2000; Young, 1991). 
2. Prognathism and dorsoventral compression of head: (0) orthognathous, subprognathous or prognathous with dorsal side distinctly sloping; (1) prognathous, dorsal side nearly horizontal and parallel to body axis. A very distinctly prognathous head with nearly horizontal dorsal side is present in some first instar larvae of Rhipiphoridae (Lawrence, 1999; coded as 0\&1) and in larvae of Prostomidae (Schunger et al., 2003), Synchroidae, Mycteridae, Boridae, Pythidae, Pyrochroidae, Salpingidae, Anthicidae, Euglenidae and Scraptiidae (Lawrence, 1991; Young, 1991; Hemp \& Dettner, 2003: Fig. 8).

3. Orthognathism and globular head shape: (0) not orthognathous and globular; (1) globular, mouthparts ventrally directed. A globular, orthognathous head is found in larvae of Ciidae, Mordellidae, Rhipiphoridae (post-triungulin larvae, coded as $0 \& 1$ ) and Meloidae (post-triungulin larvae, coded as 0\&1) (Lawrence, 1991; Pollock et al., 2000; Selander, 1991).

4. Unpaired median dorsal endocarina: (0) absent; (1) present. A dorsomedian endocarina is present in larvae of Ciidae (absent in Sphindocis, coded as 0\&1), Tetratomidae (only in Penthe, coded as 0\&1), Melandryidae (part., sometimes Y-shaped, coded as 0\&1), Mordellidae, Colydidae (part., sometimes Y-shaped or paired, coded as 0\&1), Zopheridae (part., sometimes Y-shaped, coded as 0\&1), Ulodidae (Fig. 6c), Mycteridae (part.) and Anthicidae (Hemp \& Dettner, 2003: Fig. $8 b)$.

5. Paired dorsal endocarina: (0) absent; (1) present. A paired dorsal endocarina is present in larvae of Colydidae (part., sometimes unpaired or Y-shaped, coded as 0\&1), Monommatidae and Salpingidae (excl. Inopeplinae and Othniinae, coded as 0\&1) (Young, 1991) and Anthicidae [part., Pergetus; Young, 1991 (as member of Pedilinae)].

6. Y-shaped dorsal endocarina: (0) absent; (1) present. An $\mathrm{Y}$-shaped dorsal endocarina is present in larvae of Melandryidae (part., coded as 0\&1), Colydidae (part., coded as 0\&1), Zopheridae (part., coded as 0\&1; Ślipiński \& Lawrence, 1999), Stenotrachelidae (= Cephaloidae) (part., coded as 0\&1) and Oedemeridae (Fig. 3b) (Lawrence, 1991).

7. Frontoclypeal suture: (0) absent or only vaguely indicated; (1) distinctly present. The frontoclypeal suture is usually absent in tenebrionoid larvae, but distinctly present in some larvae of Tetratomidae, Melandryidae, Zopheridae (Ślipiński \& Lawrence, 1999), Ulodidae (Fig. 3c), Stenotrachelidae, Oedemeridae (Fig. 3b), in larvae of Physiomorphus (Mycteridae; Pollock et al., 2000) and in larvae of Archeocrypticidae, Ciidae, Mordellidae (Fig. 12b), Tenebrionidae (Lawrence, 1991), Mycteridae (part., present in Physiomorphus, coded as 0\&1; Pollock et al., 2000) and Scraptiinae (Young, 1991; coded as $0 \& 1)$.

8. Length reduction of coronal suture: (0) not shortened, more than $20 \%$ of head capsule length; (1) less than $20 \%$ of head capsule length or absent. The coronal suture is distinctly shortened or absent in larvae of Mycetophagidae, Archeocrypticidae, Colydiidae (part., coded as $0 \& 1$ ), Rhipiphoridae (first instar larvae, coded as 0\&1), Monommatidae, Prostomidae, Zopheridae (part., coded as 0\&1; Ślipiński \& Lawrence, 1999), Ulodidae (Fig. 3c), Perimylopidae, Stenotrachelidae (Stenotrachelinae, coded as 0\&1), Mycteridae, Boridae, Pythidae, Pyrochroidae, Salpingidae (Lawrence, 1991), Anthicidae (Hemp \& Dettner, 2003), Euglenidae and Scraptiidae (Young, 1991).

9. Elongation of coronal suture: (0) not elongated, $20-50 \%$ of head capsule length; (2) more than $50 \%$ of head capsule length. A distinctly elongated epicranial stem is present in larvae of Mordellidae (Costa et al., 1988) and Oedemeridae (part., coded as 0\&1; Lawrence, 1991).

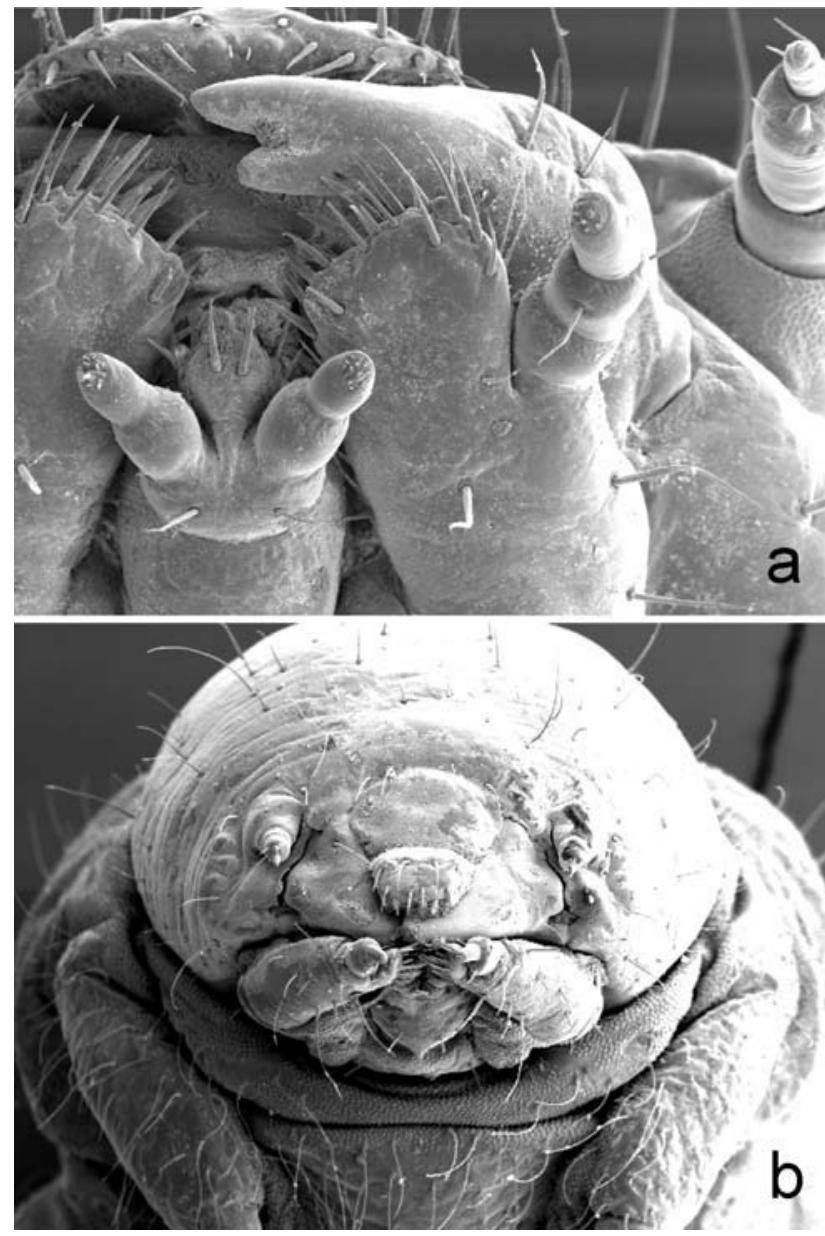

Figs 12a-b: SEM micrographs. a - Pseudolycus sp., mouthparts, ventral view; c-Curtimorda sp., head, ventral view.

10. Curve of coronal suture: (0) absent; (1) present. The coronal suture is moderately long and conspicuously bent to the left in larvae of Pterogeniidae (Lawrence, 1977).

11. Shape of frontal arms: (0) lyriform; (1) V-shaped. The frontal arms are lyriform in most larvae of Tenebrionoidea (Figs $3 \mathrm{c}, \mathrm{d})$. They are V-shaped or U-shaped in Ciidae, Ripiphoridae (post-triungulin larvae, coded as 1 [absent in first instar larvae]), Melandryidae (part., coded as 0\&1; Fig. 3a), Colydiidae (part., coded as 0\&1), Zopheridae (part., coded as 0\&1; Ślipiński \& Lawrence, 1999), Chalcodryidae (joined anteriorly by a transverse ecdysial line, see below), Tenebrionidae (with few exceptions), Stenotrachelidae (part., coded as $0 \& 1$ ) and Oedemeridae (Fig. 3b; lyriform in Calopus, coded as 0\&1). Lyriform frontal arms are present in triungulin larvae of Lytta and Meloe (Meloidae; Selander, 1991: Figs 34.702-704) but may be V- or U-shaped or reduced in other representatives of the family (coded as 0\&1). The frontal arms are absent in larvae of Mordellidae (coded as - ).

12. Frontal arms: (0) not forked; (1) forked. The frontal arms are forked in some larvae of Tetratomidae (Lawrence, 1991).

13. Transverse ecdysial line: (0) absent; (1) present. A transverse ecdysial line is present in larvae of Pterogeniidae, Chalcodryidae and Scraptiidae (part., Anaspis, coded as 0\&1) (Lawrence, 1991; Young, 1991).

14. Hypostomal rods: (0) present; (1) absent. Hypostomal rods are absent from larvae of Ciidae, Tetratomidae (part., absent only in Penthe, coded as 0\&1), Melandryidae (part., absent in some Melandryinae: Xylita, Rushia, 2 pairs present in 
Eustrophinae, coded as 0\&1), Colydidae (part., coded as 0\&1), Prostomidae, Zopheridae (part., absent in Zopherinae and most Nosoderminae, coded as $0 \& 1$ ), Perimylopidae, Chalcodryidae, Tenebrionidae, Cephaloidea (part., coded as 0\&1), Oedemeridae (part., present in Calopus, coded as 0\&1), Trictenotomidae, Pythidae (Fig. 4d; Lawrence, 1991), Anthicidae (Hemp \& Dettner, 2003: Fig. 8a), Euglenidae and Scraptiidae (part., coded as 0\&1) (Young, 1991).

15. Ventral epicranial ridges: (0) absent; (1) present. Ventral epicranial ridges are absent in most larvae of Tenebrionoidea (Fig. $4 \mathrm{a}-\mathrm{c}$ ) but are present in larvae of Ciidae, Tenebrionidae, (part., Toxicini, coded as 0\&1; Lawrence \& Spilman, 1991), Trictenotomidae and Pythidae (Fig. 4d) (Lawrence, 1991; Young, 1991).

16. Gula with distinct internal gular ridges: (0) absent; (1) present. The presence of a posteriorly diverging, transverse or moderately elongated gula, which is laterally limited by distinct internal gular ridges (Fig. 4), is a typical feature of tenebrionid larvae (Lawrence, 1977, 1991). It is absent in larvae of Mordellidae (Fig. 12b; Costa et al., 1988; Lawrence, 1991). The gula is parallel-sided in some larvae of Tenebrionoidea (e.g., Anthicidae; Hemp \& Dettner, 2003) like in larvae of Cleroidea (Beutel \& Pollock, 2000).

17. Posterior tentorial grooves: $(0)$ close to hind margin of head capsule; (1) shifted anteriorly. The posterior tentorial grooves, i.e. the bases of the posterior arms, and the tentorial bridge are more or less distinctly shifted anteriorly in all larvae of Tenebrionoidea examined (Figs 4, 7; Lawrence, 1977: Fig. 6) except for Mordellidae (Lawrence, 1991). It is most likely correlated with the presence of a well developed gula and gular ridges (Fig. 7).

18. M. frontoepipharyngalis: (0) present; (1) absent. This muscle was found in all larvae of Tenebrionoidea examined (Fig. 5) (as in larvae of the cucujoid families; Beutel \& Ślipiński, 2001), with the exception of Prostomidae (Schunger et al., 2003).

19. Shape of mandibles: (0) symmetric; (1) asymmetric. The mandibles are asymmetric in larvae of most groups of Tenebrionoidea, but symmetric in some larvae of Ciidae (Lawrence, 1991), in Melandryidae (part., coded as 0\&1; Lawrence et al., 1999), Mordellidae, Colydiidae, Monommatidae, Zopheridae (part., coded as 0\&1), Meloidae (triungulin larvae; Selander, 1991: Figs 34.699, 702, 703), Mycetridae (part., coded as 0\&1) and Salpingidae (excl. Othniinae and Inopeplinae; coded as 0\&1) (Lawrence, 1991; Young, 1991).

20. Mola: (0) present; (1) absent or strongly reduced. The mandibular mola is absent in most larvae of Ciidae (occasionally present and transversely ridged; Lawrence, 1991: Fig. 34.637, coded as $0 \& 1$ ), Tetratomidae (part., replaced by a membranous lobe in Penthe, coded as 0\&1), Melandryidae (part., coded as $0 \& 1$, Fig. 6a; present and tuberculate in Hallomeninae), Mordellidae, Colydiidae (part., coded as $0 \& 1$ ), Monommatidae, Perimylopidae (Watt, 1967), Mycteridae (part., coded as $0 \& 1$ ), Salpingidae (excl. Othniinae and Inopeplinae part., coded as 0\&1) (Lawrence, 1991; Young, 1991). The molar area is strongly modified in Ulodidae (Fig. 6c; coded as 1).

21. Molar tooth on left mandible: (0) absent; (1) present. A molar tooth is present on the left mandible of larvae of Mycetophagidae (Lawrence, 1991: Fig. 34.632), Archeocrypticidae, Ciidae (part., Lawrence, 1991: Fig. 34.635), Prostomidae (Schunger et al., 2003), Tenebrionidae (part., coded as 0\&1), Stenotrachelidae, Oedemeridae, Boridae, Pythidae (Fig. 6d), Pyrochroidae, Othniinae, Inopeplinae [coded as 1 for Salpingidae (mola reduced in Salpingidae sensu Lawrence, 1991)], Anthicidae, Euglenidae and Scraptiidae (Lawrence, 1991: Fig. 34.741; Young, 1991). Moderately prominent molar teeth are present on both mandibles in larvae of Mycteridae (Lawrence, 1991: Fig. 34.713, 714; Pollock et al., 2000, scored as 0 )

22. Molar surface: (0) asperities or tubercles; (1) transverse ridges. A molar surface with asperities or tubercles, usually arranged in rows is present in larvae of tenebrionoid groups considered primitive by Lawrence (1977) (e.g., Mycetophagidae, Archeocrypticidae). Transverse ridges are present in larvae of Pterogeniidae, (Lawrence, 1977: Figs 16-23), Ciidae (part., coded as $0 \& 1$, see above), Tetratomidae (part., Pisenus, tuberculate in Eupisenus, mola absent in others, coded as 0\&1), Colydiidae (part., coded as 0\&1), Prostomidae, Synchroidae, Zopheridae (part., coded as 0\&1), Tenebrionidae (part., coded as 0\&1), Stenotrachelidae, Oedemeridae (Fig. 6b), Mycteridae (part., coded as 0\&1), Boridae, Trictenotomidae, Pythidae, Othniinae, Inopeplinae (part., coded as 0\&1 for Salpingidae) and Pyrochroidae (Lawrence, 1977, 1991; Young, 1991). The ridges may alternate with rows of small deep pits (e.g. Pterogeniidae) or may be separated by deep troughs (e.g. Synchroidae, Boridae, Pythidae, Pyrochroidae, Othniinae) or may be shallow without a sign of a primarily tuberculate condition (e.g. Prostomidae, Stenotrachelidae, Oedemeridae) (Lawrence, 1977; Young, 1991).

23. Prostheca: (0) present; (1) absent. Unlike in larvae of the cucujoid families, a prostheca is almost always absent in tenebrionoid larvae (Fig. 7; Lawrence, 1977). Hyaline mandibular processes may occur in some families (e.g. Ciidae; Lawrence, 1991). However, the homology with the prostheca is very doubtful (coded as 1).

24. Articulating area of maxilla: (0) present; (1) absent. The articulatory area is absent in larvae of Ciidae (excl. Sphindocis, coded as 0\&1), Ripiphoridae and Meloidae (Selander, 1991; Lawrence et al., 1999).

25. Shape and sclerotisation of articulating area: (0) not pad-like, unsclerotised; (1) pad-like. A pad-like maxillary articulatory area is present in larvae of Synchroidae (Young, 1991), Prostomidae, Mycteridae, Boridae, Pythidae (Fig. 4d), Pyrochroidae, Salpingidae, Anthicidae (Young, 1991; Hemp \& Dettner, 2003: Figs 8a, 11), Euglenidae and Scraptiidae (Young, 1991). The articulatory area is absent in larvae of Ciidae (excl. Sphindocis, coded as 0\&1) (Costa et al., 1988; Lawrence, 1991).

26. Galea: (0) present as separate sclerite; (1) fused with lacinia. Like in other cucujiform larvae an undivided mala is present in all tenebrionoid larvae (Figs 4, 7) with the exception of Ciidae (Lawrence, 1991; Costa et al., 1988: pl. 100, Fig. 7).

27. Apicomesal margin of mala: (0) without projection; (1) with one or several fixed teeth. One or several mesally directed tooth-like projections (uncus) are present on the mala of protocucujid larvae (Ślipiński, 1998), Tetratomidae (part., coded as $0 \& 1$ ), Colydiidae (part., coded as $0 \& 1$ ), Monommatidae, Zopheridae (part., coded as 0\&1; Ślipiński \& Lawrence, 1999), Ulodidae (small tooth-like projection; Fig. 7c), Tenebrionidae (part., coded as $0 \& 1$ ), Stenotrachelidae (part., coded as 0\&1), Oedemeridae (Fig. 7b), Mycteridae, Trictenotomidae, Pythidae (Fig. 7d), Pyrochroidae and Othniinae (coded as 0\&1 for Salpingidae) (Lawrence, 1991; Costa et al., 1988). A distinct setiferous projection is present in larvae of Prostomidae (coded as 0$)$.

28. Shape of mala: (0) acuminate or rounded; (1) truncate. The mala is rounded in most larvae of Tenebrionoidea. It is apically truncate in larvae of Archeocrypticidae, Pterogeniidae, Melandryidae (part., coded as 0\&1), Colydiidae, Monommatidae, Zopheridae (Lawrence, 1991), Ulodidae (Fig. 7c), Tenebrionidae (part., coded as 0\&1), Stenotrachelidae, Meloidae (part., coded as 0\&1; Lawrence et al., 1999), Trictenotomidae (part., coded as $0 \& 1$ ), Pyrochroidae and Othniinae (coded as $0 \& 1$ for 
Salpingidae) (Lawrence, 1991; Lawrence et al., 1999; Young, 1991).

29. Apex of lacinia or mala: (0) not cleft; (1) cleft. The apex of the mala is cleft in larvae of Melandryidae (part., only in Osphyinae, coded as 0\&1), Monommatidae, Prostomidae, Synchroidae, Zopheridae, Ulodidae (Fig. 7c), Perymylopidae, Stenotrachelidae (part., coded as $0 \& 1$ ), Trictenotomidae, Pythidae, Othniinae (coded as 0\&1 for Salpingidae) (Young, 1991: Fig. $34.729 \mathrm{e}$ ) and Scraptiidae (part., coded as 0\&1: Anaspidinae.) (Lawrence, 1991; Böving \& Craighead, 1931).

30. Hypopharyngeal sclerome: (0) absent or transverse bar, not molar-like; (1) molar-like. A molar-like hypopharyngeal sclerome, which interacts with the mandibular mola is present in larvae of Archeocrypticidae, Pterogeniidae, Tetratomidae (part., coded as $0 \& 1$, molar-like in Pisenus and Hallomeninae), Synchroidae, Zopheridae (part., coded as 0\&1), Ulodidae, Stenotrachelidae, Oedemeridae, Trictenotomidae, Pythidae, Pyrochroidae, Othniinae (coded as 0\&1 for Salpingidae) and Scraptiidae (part., coded as 0\&1) (Lawrence, 1991; Lawrence et al., 1999; Young, 1991).

31. M. craniocardinalis: (0) well developed; (1) absent or thin and parallel with $M$. craniolacinialis. M. craniocardinalis could not be identified in larvae of Colydiidae, Melandryidae (Figs 7a, 8) and Ulodidae (Fig. 7c), and is thin and parallel with M. craniolacinialis in larvae of Oedemeridae, Pythidae (Fig. 7d), Pyrochroidae and Mordellidae (Fig. 9a).

32. M. tentoriopharyngalis posterior: (0) one group of muscles, origin from the tentorial bridge or ventral wall of head capsule; (1) 2-3 groups of muscles with origin from the gular ridges and the posterior tentorial arm. M. tentoriopharyngalis posterior is divided into several subunits, which arise from the gular ridges and the posterior tentorium in the larvae of Tenebrionoidea examined (less strongly developed in Orchesia and with origin shifted to postoccipital ridge).

33. Anterior prosternal plate $(=$ cervicosternum + presternum, cervicosternum s. Lawrence, 1991): (0) undivided; (1) divided into 3 sections. The anterior prosternal plate is divided into three sections by parallel longitudinal lines in larvae of Boridae, Pythidae (Fig. 10d), Pyrochroidae and Othniinae (coded as 0\&1 for Salpingidae) (Young, 1991).

34. Stigma I: (0) not elevated; (1) on spiracular tube. The mesothoracic stigma is located on a spiracular tube in larvae of Derodontidae, Prostomidae (Schunger et al., 2003: Fig. 9a) and Salpingidae (part., not in Othniinae and Rhinosinus, coded as 0\&1) (Young, 1991).

35. Legs: (0) well developed; (1) partly reduced. Well developed 5-segmented legs are usually present in larvae of Tenebrionoidea (Figs 2, 10). They are indistinctly 3- or 4-segmented in larvae of Mordellidae. Reductions occur also in post-triungulin larvae of Rhipiphoridae (Selander, 1991) and Meloidae (coded as 0 ).

36. Length of segment VIII: (0) not longer than segment VII: (1) c. twice as long as segment VII. Segment VIII is approximately twice as long as segment VII in larvae of Mycteridae (Lawrence, 1991; Pollock et al., 2000), Boridae and Pyrochroidae (Young, 1991).

37. Tergum IX: (0) not plate-like and horizontal, not forming entire terminal segment; (1) plate-like, horizontal, strongly extending ventrally to form the entire terminal segment (urogomphal plate). A characteristic plate-like, ventrally extending tergite IX, which forms the apical part of the abdomen (= urogomphal plate) is present in larvae of Prostomidae, Mycteridae, Boridae, Trictenomidae, Pythidae (Fig. 11d), Pyrochroidae, Salpingidae, Anthicidae (Hemp \& Dettner, 2003: fig. 20), Euglenidae and Scraptiidae (part., coded as 0\&1) (Lawrence, 1977, 1991; Lawrence et al., 1999; Young, 1991).
38. Articulation between segment VIII and tergum IX: (0) absent; (1) present. An articulation between segment VIII and tergite IX is present in larvae of Prostomidae (Schunger et al., 2003: Fig. 10e, f), Pyrochroidae (part., not in Pedilinae, coded as 0\&1), Mycteridae and Boridae (Lawrence, 1977, 1991; Young, 1991).

39. Ventral part of tergite IX: (0) not subdivided; (1) subdivided into several plates. The ventral part of tergite IX is subdivided into several plates in Trictenotomidae and Pythidae (Fig. 11d) (Lawrence, 1991; Young, 1991).

40. Urogomphi: (0) present; (1) absent. Fixed urogomphi are present in larvae of most groups of Tenebrionoidea (Fig. 11) (Young, 1991; Lawrence, 1991; Lawrence et al., 1999). They are absent from larvae of Thrimolus (Mycetophagidae), Ciidae (part., occasionally a with single median process or more than two processes, coded as $0 \& 1$ ), Melandryidae (part., coded as 0\&1), Mordellidae (part., coded as 0\&1), Rhipiphoridae, Colydiidae (part., coded as $0 \& 1$, only rarely with median spine), Chalcodryidae, Tenebrionidae (part., coded as 0\&1), Stenotrachelidae (part., coded as $0 \& 1$ ), Meloidae, Oedemeridae (part., coded as 0\&1) and Scraptiidae (part., coded as 0\&1) (Lawrence, 1991; Young, 1991).

41. Single, median process: (0) present; (1) absent. A single median process is present in some larvae of Ciidae, Mordellidae, Colydiidae and Tenebrionidae (Lawrence, 1999; Lawrence \& Spilman, 1991).

42. Paired pits between urogomphi: (0) absent; (1) present. Two pits are present in larvae of Mycteridae (part., coded as 0\&1), Pyrochroidae (Lawrence, 1977, 1991; Pollock et al., 2000; Young, 1991)

43. Unpaired pit between urogomphi: (0) absent; (1) present. One urogomphal pit is present in larvae of Melandryidae (part., Xylita and Rushia, coded as 0\&1), Colydiidae (part., coded as 0\&1), Monommatidae, Oedemeridae (part., present only in Calopus, coded as 0\&1), Pythidae (part., coded as 0\&1) (Lawrence, 1991; Young, 1991).

44. Sternite IX: (0) not enclosed by sternum VIII; (1) partly enclosed by sternum VIII. Sternite VIII is posteriorly excavated and partly enclosing sternite VIII in larvae of Mycteridae, Boridae, Pyrochroidae and Inopeplinae (coded as 0\&1 for Salpingidae) (Young, 1991), not in Prostomidae, (Schunger et al., 2003).

45. Single asperity on sternum IX: (0) absent; (1) present. A single asperity is present in Melandryidae (part., Hallomeninae, coded as 0\&1), Synchroidae, Boridae (part., coded as $0 \& 1$ ), Mycteridae (part., coded as $0 \& 1$ ) and Salpingidae (excl. Othniinae and Inopeplinae; coded as 0\&1) (Lawrence, 1991; Young, 1991).

46. Small anterolateral group of asperities on sternum IX: (0) absent; (1) present. A small anterolateral group of asperities is present in Calopus (usually absent in Oedemeridae, coded as $0 \& 1$ ), Mycteridae (part., coded as $0 \& 1$ ), Pyrochroidae (part., only in Pedilinae, coded as 0\&1) and Inopeplinae (part., coded as 0\&1 for Salpingidae) (Lawrence, 1991; Young, 1991).

47. Anterior row of asperities on sternum IX: (0) absent; (1) present. An anterior row of asperities is present in larvae of Trictenotomidae, Pythidae (Fig. 11d), Pyrochroidae and Othniinae (part., coded as 0\&1 for Salpingidae) (Lawrence, 1991; Young, 1991).

48. Posterior row of asperities on sternum IX: (0) absent; (1) present. A posterior row of asperities is present in larvae of Ciidae (part., coded as $0 \& 1$ ), Colydiidae (part., coded as 0\&1) and Prostomidae (Lawrence, 1991; Lawrence et al., 1999; Schunger et al., 2003: Fig. 10e).

49. Small dentiform plates on sternum IX: (0) absent; (1) present. Sternite VIII is produced in a series of small dentiform 


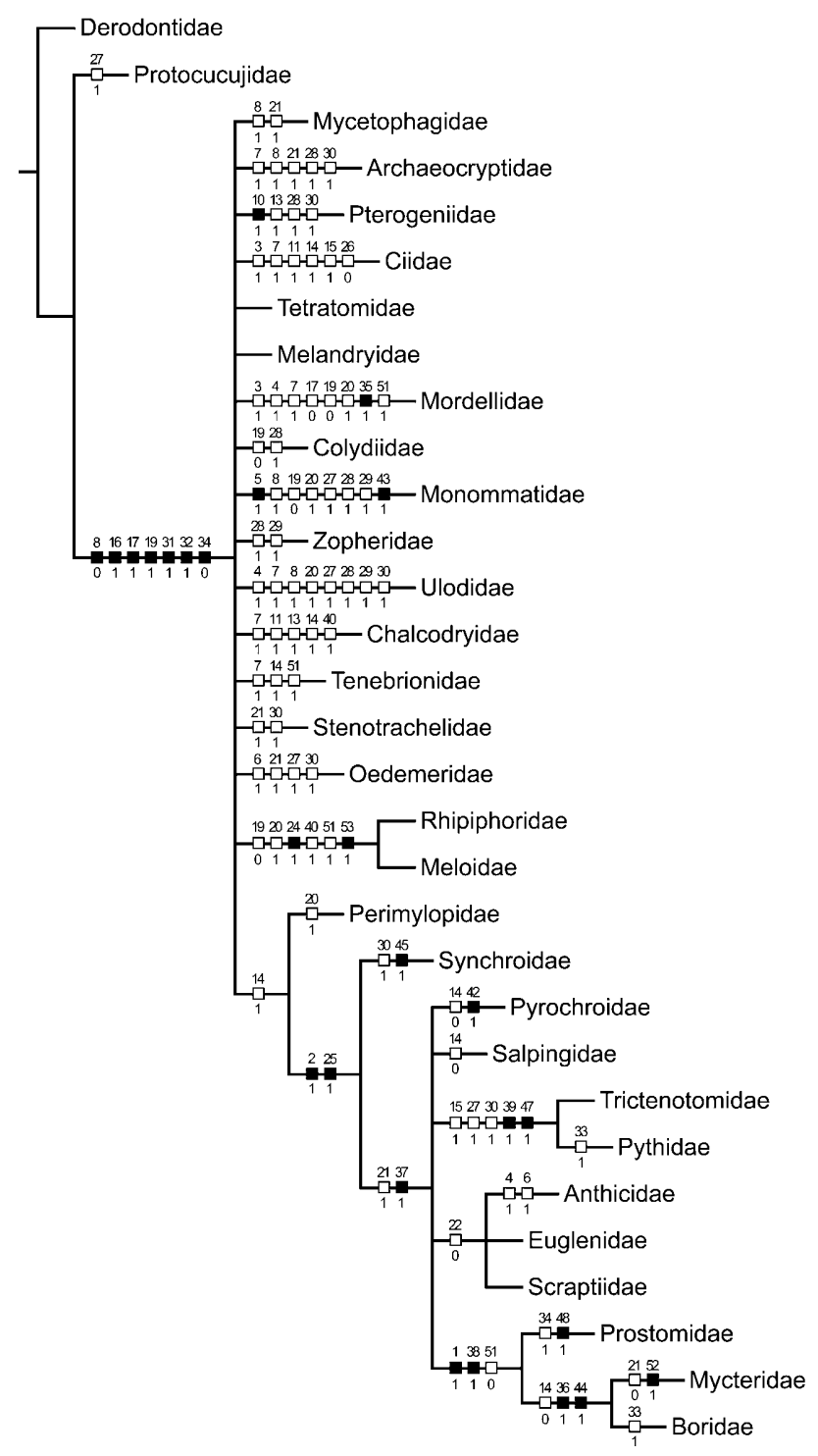

Fig. 13. Strict consensus tree $(L=120)$ of 2650 most parsimonious cladograms with a length of 85 steps. Characters marked by full squares are non-homoplastic (character states below squares).

plates in larvae of Boridae [part. (Boros), coded as 0\&1; Young, 1991].

50. Annular-uniforous abdominal spiracles: (0) absent; (1) present. The spiracles are annular-biforous in most tenebrionid larvae. Annular-uniforous spiracles are present in Ciidae (part., annular-biforous in Sphindocis, coded as 0\&1), Melandryidae (part., coded as $0 \& 1$ ) and Chalcodryidae (part., coded as $0 \& 1$ ) (Lawrence et al., 1999).

51. Annular abdominal spiracles: (0) absent; (1) present. Annular spiracles are present in Mycetophagidae (part., coded as $0 \& 1$ ), Ciidae (part., coded as 0\&1), Melandryidae (part., coded as $0 \& 1$ ), Mordellidae, Rhipiphoridae (post-triungulin larvae), Perymylopidae, Chalcodryidae (part., coded as $0 \& 1$ ), Tenebrionidae, Meloidae, Oedemeridae (part., coded as $0 \& 1$ ), Scraptiidae (part., coded as 0\&1), Boridae (part., coded as 0\&1), Trictenotomidae, Pythidae (part., coded as 0\&1), Pyrochroidae, Salpinigidae (part., not in Othniinae, Inopeplinae and some Salpingidae sensu Lawrence, 1991; coded as 0\&1), Anthicidae, Euglenidae and Scraptiidae (part., coded as 0\&1) (Lawrence, 1991; Lawrence et al., 1999; Selander, 1991).
52. Annular-multiforous abdominal spiracles: (0) absent; (1) present. Annular-multiforous spiracles occur in larvae of Chalcodryidae (part., coded as $0 \& 1$ ), Oedemeridae (part., coded as 0\&1) and Mycteridae (Lawrence, 1991; Lawrence et al., 1999).

53. Hypermetamorphosis: (0) absent; (1) present. Rhipiphoridae and Meloidae are characterised by hypermetamorphosis. However, the triungulin and post-triungulin larvae differ distinctly in both families. The hypermetamorphosis is correlated with parasitism in Rhipiphoridae, but with specialised predatory habits in larvae of Meloidae. Meloid larvae feed on eggs, immatures and provisions of other insects in the T- (triungulin) and FG phase (Selander, 1991).

\section{Results of the analysis}

The analyis (NONA) with Salpingidae sensu Lawrence $\&$ Newton (1995) as terminal taxon yielded 2650 minimal length trees with 85 steps (CI 0.54, RI 0.71). The strict consensus tree (Fig. 13, with apomorphies mapped on it) is poorly resolved. 815 equally parsimonous trees with 101 steps were obtained when Inopeplinae, Othniinae and Salpingidae sensu Lawrence, 1991, and Pedilinae and Pyrochroidae sensu Lawrence, 1991 were treated as separate terminals (strict consensus tree: 158 steps, $\mathrm{CI}=0.46$, RI 0.69).

\section{DISCUSSION}

Considering the complexity and morphological heterogeneity of Tenebrionoidea, it was not surprising for us that the larval data presented here were not sufficient for a satisfying clarification of the relationships of the families. Therefore, the results have to be treated as very preliminary, and the characters presented above may be mainly considered as a basis for more comprehensive future analyses.

Tenebrionoidea (incl. Ciidae and Prostomidae) was well supported as a clade by several larval autapomorphies (Figs 13,14). Potential synapomorphies of all tenebrionoid families are a posteriorly diverging gula with well developed gular ridges (16.1), anteriorly shifted posterior tentorial arms $(17.1$; in contrast to Cleroidea and Cucujoidea), asymmetric mandibles (19.1), the absence or vestigial condition of $M$. craniocardinalis (31.1), and the subdivision of $\mathrm{M}$. tentoriopharyngalis posterior into several bundles arising from the gular ridges (32.1). Whether some or all of these characters are indeed tenebrionoid autapomorphies is uncertain at this stage. However, it is rather obvious that modifications of the posteroventral head capsule and tentorium of larvae played an important role in the early evolution of the superfamily. Two other features are charactersistic for tenebrionoid larvae, but were not confirmed as autapomorphies here: the absence of the prostheca (possible exception in Ciidae: 23.0; Lawrence, 1991), and a rounded or truncate maxillary mala (28.0/1).

Plesiomorphic with respect to the cleroid-cucujoid lineage (Beutel et al., 2000; Beutel \& Ślipiński, 2001) is the absence of a maxillolabial complex (Cucujoidea part. + Cleroidea; Beutel \& Ślipiński, 2001: Figs 11-12), the unmodified connection of the posterior tentorial arms and the tentorial bridge (separated in Cucujoidea part. + 
Cleroidea; Beutel \& Ślipiński, 2001), and the absence of a hypopharyngeal subcomponent of $\mathrm{M}$. tentoriostipitalis (Beutel \& Ślipiński, 2001; Beutel \& Pollock, 2000).

Apart from the few features shared by all or most tenebrionoid larvae, the group is highly heterogenous in terms of larval morphology. The larval body is generally subparallel (Fig. 1) and a slightly flattened thorax and abdomen may be considered as a groundplan condition of the superfamily [e.g., Mycetophagidae, Archeocrypticidae, Melandryidae (Fig. 2a), Zopheridae (Fig. 2c); Lawrence, 1991]. However, distinctly different body shapes have evolved in correlation with different habits. A nearly cylindrical body seems to be typical for larvae boring in wood or compact mushroom fruiting bodies (Ciidae, Mordellidae; Costa et al., 1988; Lawrence, 1991), c-shaped and grub-like bodies are correlated with specialised developmental strategies (post-triungulin larvae of Rhipiphoridae and Meloidae), and a strongly flattened condition (1.1) has apparently evolved as an adaptation to subcortical habits [e.g., Prostomidae, Pythidae (Fig. 2d), Pyrochroidae]. However, life under bark is not necessarily correlated with a flattened body. Thorax and abdomen are subcylindrical in the larvae of Bitoma (Colydiidae), which also live in subcortical habitats.

The shape of the head capsule also varies greatly, usually in correlation with the body shape. A subprognathous or prognathous head with anteriorly sloping dorsal side may represent the ancestral state (e.g., Melandryidae, Colydiidae; Fig. 2a-c). A globular head capsule with ventrally oriented mouthparts (3.1) has evolved in Ciidae and Mordellidae (Fig. 12b). This condition is possibly correlated with an elongate coronal suture in both families (9.1) and with a reduced gula in Mordellidae. A distinctly prognathous head, with almost horizontal dorsal side and anteriorly directed mouthparts is found in all larvae with strongly flattened body (e.g., Prostomidae, Pythidae, Pyrochroidae, Boridae; Fig. 2d), but also in some other taxa (e.g., Synchroidae).

Prognathism is not correlated with predacious habits as in other groups (Adephaga, Hydrophiloidea, Cantharoidea, Cleroidea; Beutel, 1993, 1995, 1999; Beutel \& Pollock, 2000), but may facilitate penetration into crevices. In contrast to cleroid larvae which are also characterised by a distinctly prognathous head (slightly inclined in Phycosecis; Beutel \& Pollock, 2000), the prognathous head capsules of tenebrionoid larvae are not parallel-sided, but almost always distinctly rounded laterally (e.g., Prostomidae, Pyrochroidae; not in Synchroidae). An unusual and autapomorphic character is the strong asymmetry of the larval head of Prostomidae (Schunger et al., 2003).

Endocarinae, which serve as additional muscle attachment areas and strengthen the head capsule, have apparently evolved several or many times independently. They occur as median-, paired or Y-shaped ridges (Fig. 3b; chars. 4-6), and may be present or absent or variously shaped in representatives of a single family (e.g., Ciidae, Tetratomidae, Melandryidae, Colydiidae).

The length of the coronal suture varies considerably and this is likely correlated with the head shape (Fig. 3; see above). A shortened or absent coronal suture (8.1) is usually found in larvae with a strongly prognathous head (e.g., Prostomidae, Pyrochroidae, Pythidae; Figs 1d, 3d), and an elongate coronal suture in larvae with a globular head capsule (e.g., Mordellidae). A distinctly asymmetric coronal suture as is found in larvae of Pterogeniidae (Lawrence, 1977) is likely an autapomorphy of this family.

The frontal arms are probably primarily lyriform with distinct lateral loops (11.0). This condition is found in most tenebrionoid families (Figs 3c, d) and in the outgroup taxa. V-shaped frontal arms occur in several groups [e.g., Ciidae, Melandryidae part. (Fig. 3a), Zopheridae part., Tenebrionidae part., Stenotrachelidae part., Oedemeridae part. (Fig 3b); Costa et al., 1988; Lawrence, 1991]. Forked frontal arms occur within Tetratomidae. The absence of the frontal arms is likely autapomorphic for Mordellidae, and this seems to be characteristic for boring larvae with a globular head (Lawrence, pers. comm.). An unusual feature is the presence of a transverse ecdysial line connecting the frontal arms. However, the results of the analysis show that this character state has evolved three times independently. It is apparent that the condition of the frontal arms is of limited value for the phylogenetic reconstruction of Tenebrionoidea.

Posteriorly divergent hypostomal ridges (Fig. 4a-c; char. 14) are probably present in the groundplan of the superfamily and were lost several times independently [e.g., Tetratomidae part., Melandryinae part., Zopheridae part., Trictenotomidae, Pythidae (Fig. 4d)]. Ventral epicranial ridges are missing in most tenebrionoid larvae. It is likely that they have evolved several times independently (e.g., Ciidae, Tenebrionidae part.). At least their presence in larvae of Trictenotomidae and Pythidae (hypostomal ridges absent) may be considered as a potential synapomorphy of these families (see below).

The mandibles of tenebrionoid larvae vary considerably. Asymmetry (19.1), the presence of two or three apical teeth, a tuberculate mola $(20.0,22.0)$, and the absence of a prostheca (23.1) may be groundplan features of the superfamily, but other interpretations are possible. It is rather obvious that the mola became reduced several times independently [e.g., Tetratomidae part., Melandryidae part. (Fig. 6a), Colydiidae part., Mycteridae part.]. The presence of a tooth on the left mandible (Fig. 6d; $21.1)$ is a characteristic feature of tenebrionoid larvae. However, a reliable evolutionary interpretation of this character is very difficult at present. The tooth is likely used as a crushing device. A close functional relation between the mandibular molae and the hypopharyngeal sclerome was pointed out by Lawrence (1977). Whether the molar-like sclerome (30.1) has evolved several times independently or is a possible autapomorphy of a tenebrionoid subgroup remains an open question.

The maxillae are almost always inserted in a distinct maxillary groove (Fig. 5) with a well developed articulating membrane (24.0). The articulatory area is reduced in most ciid larvae (see below) and the specialised larvae of Rhipiphoridae and Meloidae. A pad-like modification of the membrane (Fig. 4d; 25.1) is a derived condition and a possible synapomorphy of Synchroidae, Prostom- 


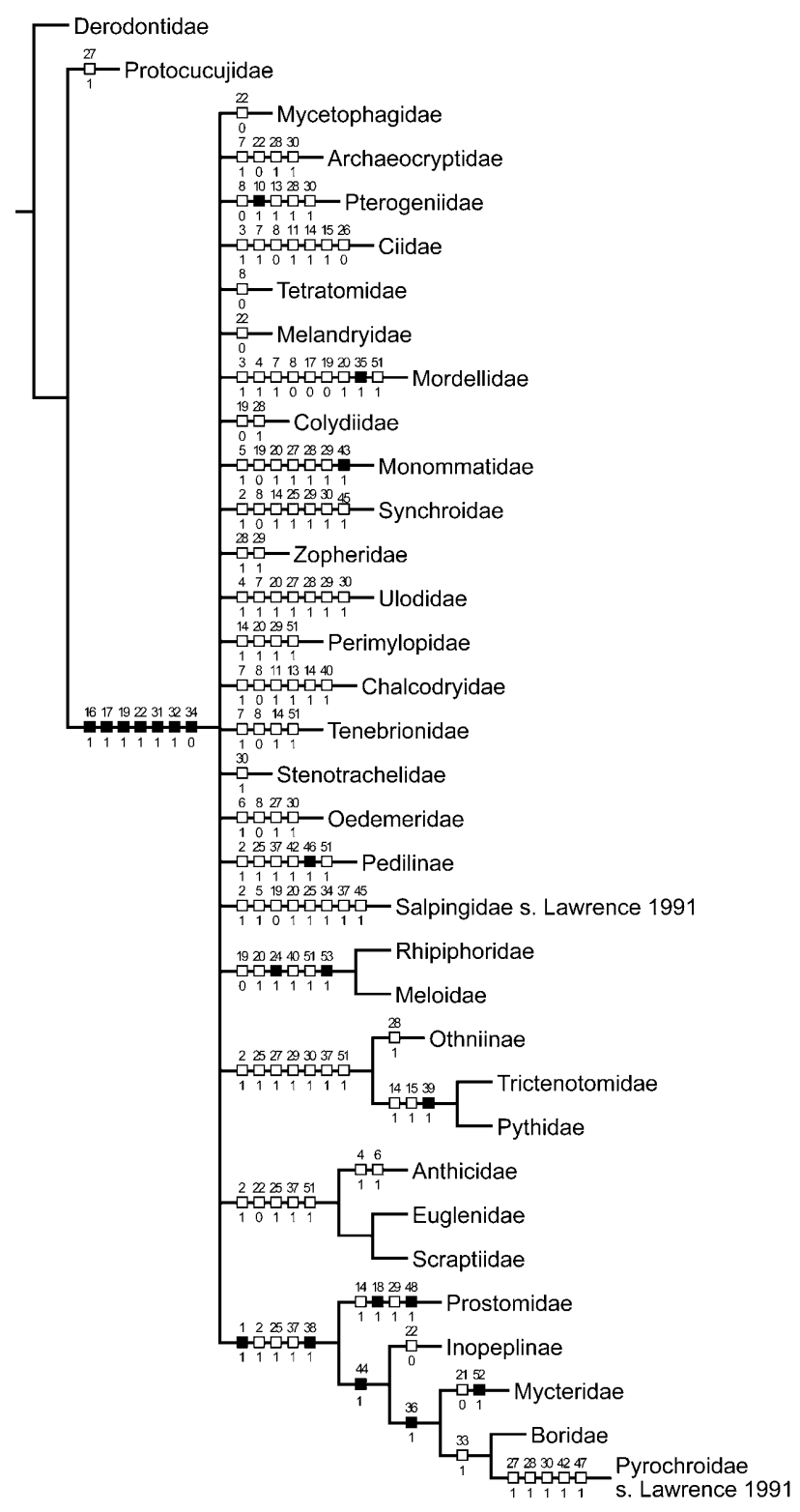

Fig. 14. Strict consensus tree ( $\mathrm{L}=158)$ of 815 most parsimonious cladograms with a length of 101 steps. Inopeplinae, Othniinae, Salpingidae sensu Lawrence, 1991, Pedilinae and Pyrochroidae sensu Lawrence, 1991 treated as separate terminal taxa $(\mathrm{CI}=46$, RI 51). Characters marked by full squares are non-homoplastic (character states below squares).

idae and the pythid-salpingid and anthicid-scraptiid lineage (Fig. 13).

The presence of an undivided mala is a groundplan feature of Tenebrionoidea (and Cucujiformia). The condition in Ciidae, i.e. the presence of a separate internal and external lobe (26.0) is certainly the result of reversal and an autapomorphy of this family. The presence or absence of a tooth-like projection on the mala (uncus) is highly variable even at the family level [e.g., Tetratomidae, Colydiidae, Zopheridae (Fig. 7c), Tenebrionoidae, Stenotrachelidae] and is apparently of limited value for phylogenetic reconstruction on a higher level. The rounded apex of the mala is probably a groundpan feature of Tenebrionoidea, and distinguishes their larvae from those of most groups of Cucujoidea. The truncate condition (Figs $7 \mathrm{~b}, \mathrm{~d} ; 28.1)$ has apparently evolved many times independently and varies even at the family level, like the presence or absence of an apical cleft (29.1; e.g., Melandryidae, Stenotrachelidae).

The musculature of the head of tenebrionoid larvae is characterised by the presence of a strong frontoepipharyngeal muscle (M 9; Fig. 5) (absent in Prostomis as a result of an extremely flattened head; Schunger et al., 2003), a moderately sized or weakly developed prepharyngeal dilator (M 43), dorsal and ventral postpharyngeal dilators composed of several bundles (M 46), or subcomponents (M 52; Figs 5, 7), respectively. The maxillary musculature is similar to that found in cucujoid larvae and many others. However, the cranial muscle of the cardo is very thin or even absent in most tenebrionoid larvae (Fig. 7). A tendency to reduce the premental retractors is shared with larvae of Cucujoidea and Cleroidea (Beutel \& Pollock, 2000; Beutel \& Ślipiński, 2001). At least one of the three muscles (Mm 28-30) is absent.

The cerebrum and suboesophageal complex are generally located in the posterior region of the head capsule in tenebrionoid larvae (Fig. 5). The relative size is negatively correlated with the size of the head. A complete shift of the brain to the thorax as it is found in all cleroid larvae examined (Beutel \& Pollock, 2001) was not observed in larvae of Tenebrionoidea.

Characters of the thorax were not very informative for phylogenetic reconstruction. The presence of an elevated mesothoracic spiracle (34.1) was interpreted as a plesiomorphic feature in our analysis (see above). This is obviously due to its shared presence in the two outgroup taxa (Derodontidae, Protocucujidae) and almost certainly incorrect, since this condition is absent in the vast majority of beetle larvae. A characteristic, almost certainly derived feature is the subdivision of the anterior prosternal plate (33.1). However, the results of our analysis suggest that this condition has evolved several times independently within the pythid-salpingid group. It is possible, however, that this character state is at least synapomorphic for Boridae and Pyrochroidae (Fig. 14).

Modifications of abdominal structures provide phylogenetically useful characters, especially for the pythidsalpingid lineage. A strong elongation of segment VIII (36.1) is a condition characteristic for Mycteridae, Boridae and Pyrochroidae (see below). A feature shared by Prostomidae, the pythid-salpingid lineage, and the anthicid-scraptiid lineage is the nearly horizontal, platelike tergum IX (37.1). A very unusual apomorphic character state is the articulation between segments VIII and IX (38.1). It is a shared derived condition of Prostomidae, Mycteridae, Boridae, Pyrochroidae and Inopeplinae. A feature not known from other beetles is the subdivision of the ventral part of tergite IX into several plates (39.1). This condition is found in Trictenotomidae and Pythidae (Figs 13, 14). A derived feature shared by Mycteridae, Boridae, Pyrochroidae and Inopeplinae is a sternite IX partly enclosed by sternite VIII (44.1).

The strict consensus trees (Figs 13, 14) show a low resolution. One result, which may be considered as a 
working hypothesis, is the sistergroup relationship between Synchroidae and a clade comprising Prostomidae, the pythid-salpingid lineage and the anthicidscraptiid lineage (Fig. 13). Potential synapomorphies are the distinctly prognathous head (2.1) and the pad-like maxillary articulating area (25.1). The plate-like tergum IX (37.1) is a possible synapomorphy of this group excluding Synchroidae. The monophyly of groups comprising Trictenotomidae + Pythidae seems to be well supported (see above). A clade comprising Prostomidae + (Mycteridae + Boridae) [strongly flattened body (1.1), articulation between segment VIII and tergum IX (38.1)] is supported when Salpingidae and Pyrochroidae as defined by Lawrence \& Newton (1995) are treated as terminal taxa. An elongated segment VIII (36.1) and a sternite IX enclosed by sternum VIII are potential synapomorphies of Mycteridae and Boridae. This implies parallel evolution in Pyrochroidae for both characters.

When Othniinae, Inopeplinae and Pedilinae are treated as separate terminals, the number of minimum length trees is distinctly reduced. The monophyly of Salpingidae sensu Lawrence \& Newton (1995) was not confirmed. Othniinae form a clade with Trictenotomatidae and Pythidae (Fig. 14). Pyrochroidae sensu Lawrence \& Newton (1995) were also rendered paraphyletic with Pyrochroidae sensu Lawrence (1991) isolated from Pedilinae and as sister taxon of Boridae (characters see Fig. 14). This would reduce homoplasy as it would not imply that the strongly flattened body (1.1), the elongation of segment VIII (36.1), the articulation between segment VIII and tergum IX (38.1), and the enclosure of sternite IX by sternum VIII (44.1) have evolved independently in Pyrochroidae (sensu Lawrence, 1991).

Salpingidae and Pyrochroidae as defined by Lawrence $\&$ Newton (1995) are quite heterogenous in their larval morphology and the monophyly of the groups should be critically evaluated in a cladistic study with a more comprehensive data set (e.g., adult morphology).

Another clade in our strict consensus trees is formed by Meloidae and Rhipiphoridae. This is likely an artefact as the derived features shared by both groups are probably related with the specialised life style (e.g., absence of the maxillary articulating area and mandibular mola). Mordellidae are probably not closely related to Ciidae (see Lawrence, 1991), even though they share several features with this family (shape of head and body, elongate coronal suture, distinct frontoclypeal suture, shortened antennae, reduced mola). It is likely, that these derived features have evolved with a similar life style. Larvae of Mordellidae are distinguished from most other tenebrionoid larvae by the globular head, the elongate coronal suture, the orthognathous position of the mouthparts, reduced stemmata and the subcylindrical body (see above). The absence of frontal sutures and the reduced condition of the legs are autapomorphies of the family.

The characters examined show that some taxa are isolated in terms of larval morphology within the families they are assigned to. Larval features suggest a basal position of Sphindocinae within Ciidae. Unlike other representatives of the family they possess 3-segmented antennae and a well developed maxillary articulatory membrane. Loss of antennomere III and a maxillolabial complex very similar to that of elateriform (Beutel, 1995) or cleroid larvae (Beutel \& Pollock, 2000) are potential autapomorphies of Ciinae. Orchesia may belong to a monophylum within Melandryidae, which is characterised by strongly shortened antennae and the absence of urogomphi (Figs 1d, 4a). The strongly reduced tentorium (Fig. 7a), the weakly developed M. tentoriopharyngalis posterior, and the presence of a strong transverse muscle connecting the posterior tentorial arms (Fig. 8a) are other unusual features of Orchesia, but the condition in other members of the family is unknown. Larvae of Calopus (Calopinae) are distinguished from other oedemerid larvae by several plesiomorphic features, e.g., lyriform frontal sutures, presence of 2-3 apical mandibular teeth, presence of hypostomal ridges, and well developed upturned urogomphi. Larvae of Penthe (Penthinae) differ from other tetratomid larvae by the presence of a median endocarina, a mola transformed into a membranous lobe, a long and narrow ligula, absence of the hypostomal ridges, patches of asperities on meso- and metatergites and on the abdominal tergites I-VIII, and a simple apex of the urogomphi (Lawrence, 1991).

It is obvious that the larval characters are insufficient for the clarification of tenebrionoid relationships (see above). Obvious problems are the complexity of the group, the uncertain monophyly of families (Lawrence \& Newton, 1995), and lack of information, especially on internal structures. Another major problem is the high degree of homoplasy. This is reflected by the low consistency indices (see above). Structures which are highly variable even within families are the endocarina, the coronal, frontoclypeal and frontal sutures, the hypopharyngeal ridge, the mandible, the mala, the urogomphi, the asperities of sternum IX, and the spiracles. Taxa which are highly polymorphic in their larval morphology are Tetratomidae (8 polymorphic characters), Melandryidae (15 polymorphic characters), Colydiidae (13 polymorphic characters), Zopheridae (10 polymorphic characters), and Stenotrachelidae (8 polymorphic characters). The monophyly of some of these families appears questionable considering the larval features (see also Lawrence \& Newton, 1995).

The strategy for establishing a well founded phylogeny of Tenebrionoidea should be to take a stepwise approach. Single families or potentially monophyletic subunits comprising several families should be analysed with genera or tribes as terminals, and the groundplan of these groups should be established for different stages. The analysis based on groundplans of larger subunits and a broad spectrum of characters may eventually lead to a convincing phylogenetic hypothesis for this large and complex lineage of Coleoptera.

ACKNOWLEDGEMENTS. We are greatly indebted to R. Britz (The Natural History Museum, London), J.F. Lawrence, R.A.B. Leschen (New Zealand Arthropod Collection), D.A. Pollock (ENMU Natural History Museum, Eastern New Mexico University) and S.A. Ślipiński (CSIRO, Canberra) for the gift of valu- 
able specimens. The thorough review of the manuscript by S.A. Ślipiński and D.A. Pollock is also gratefully acknowledged.

\section{REFERENCES}

Abdullah M. 1973: Larvae of the families of Coleoptera. III. Heteromera, Cucujoidea: a key to the world families including their distinguishing characters. J. Nat. Hist. 7: $535-544$

AbDullah M. 1974: Heteromera (Coleoptera): a key to the world families including their distinguishing characters in the adult stage. J. Nat. Hist. 8: 49-59.

Beutel R.G. 1995: Phylogenetic analysis of Elateriformia (Coleoptera: Polyphaga) based on larval characters. J. Zool. Syst. Evol. Res. 33(4): 145-171.

Beutel R.G. \& Pollock D.A. 2000: Larval head morphology of Phycosecis litoralis (Pascoe) (Coleoptera: Phycosecidae) with phylogenetic implications. Invertebr. Taxon. 14: 825-835.

Beutel R.G. \& ŚLIPIŃSKI S.A. 2001: Comparative study of head structures of larvae of Sphindidae and Protocucujidae (Coleoptera: Cucujoidea). Eur. J. Entomol. 98: 219-232.

Beutel R.G., Weide D. \& Bernhard D. 2000: Characters of the larval head of Mycetina cruciata (Schaller) (Coleoptera: Endomychidae) and their phylogenetic implications. Ann. Zool. 50(1): 7-14.

Böving A.G. \& CRAIGHEAD F.C. 1931: An illustrated synopsis of the principal larval forms of the order Coleoptera. Entomol. Amer. 11(1): 1-125.

Costa C., Vanin S.A. \& Casari-Chen S.A. 1988: Larvas de Coleoptera do Brasil. Museo de Zoologia, Universidade de São Paulo, São Paulo, 268 pp.

Crowson R.A. 1966: Observations on the constitution and subfamilies of the family Melandryidae (Coleoptera). Eos 41: 507-513.

DoYen J.T. \& LAWRENCE J.F. 1979: Relationships and higher classification of some Tenebrionidae and Zopheridae (Coleoptera). Syst. Entomol. 4: 333-377.

Goloboff P.A. 1999: NONA ver. 2.0. P. A. Goloboff, Tucumán, Argentina.

Hemp C. \& Dettner K. 2003: Description of larvae of the genus Formicomus Laferté and data on the life cycles of Omonadus floralis (Linné) and Notoxus monocerus (Linné) (Coleoptera: Anthicidae). Coleopt. Bull. 57: 361-368.

Jösting E.A. 1942: Die Innervierung des Skelettmuskelsystems des Mehlwurms (Tenebrio molitor L., Larve). Zool. Jb. Anat. 67: 381-460.

KÉLER S.V. 1963: Entomologisches Wörterbuch. Akademie Verlag, Berlin, 744 pp.

LAWREnCE J.F. 1977: The family Pterogeniidae, with notes on the phylogeny of the Heteromera. Coleopt. Bull. 31: 25-56.

Lawrence J.F. 1991: Classification. Phycosecidae (Cleroidea). Mycetophagidae (Tenebrionoidea), Archeocrypticidae (Tenebrionoidea), Pterogeniidae (Tenebrionoidea), Ciidae (Tenebrionoidea) (= Cisidae, Cioidae), Tetratomidae (Tenebrionoidea), Melandryidae (Tenebrionoidea) (= Serropalpidae), Mordellidae (Tenebrionoidea), Colydidae (Tenebrionoidea) (including Adimeridae, Monoedidae), Monommatidae (Tenebrionoidea), Zopheridae (Tenebrionoidea) (including Merycidae), Perimylopidae (Tenebrionoidea), Chalcodryidae (Tenebrionoidea), Cephaloidae (Tenebrionoidea) (including Nematoplidae, Stenotrachelidae), Oedemeridae (Tenebrionoidea), Mycteridae (Tenebrionoidea) (including Hemipeplidae), Trictenotomidae (Tenebrionoidea). In Stehr F.W. (ed.): Immature Insects. Vol. 2. Kendall/Hunt Publishing Company, Dubuque, Iowa, pp. 181-184, 452-453, 498-508, 512-515, 518-520, 529, 534-536, 539.

Lawrence J.F., Hastings A.M., Dallwitz M.J., Paine T.A. \& ZuRCHER E.J. 1999: Beetle Larvae of the World: Descriptions,
Illustrations, Identification, and Information Retrieval for Families and Subfamilies. CD-ROM, Version 1.1 for MSWindows. CSIRO Publishing, Melbourne.

Lawrence J.F. \& Newton A.F. JR. 1982: Evolution and classification of beetles. Ann. Rev. Ecol. Syst. 13: 261-290.

Lawrence J.F. \& Newton A.F. JR. 1995: Families and subfamilies of Coleoptera (with selected genera, notes, references, and data on family-group names). In Pakaluk J. \& Ślipiński S.A. (eds): Biology, Phylogeny, and Classification of Coleoptera: Papers Celebrating the $80^{\text {th }}$ Birthday of Roy A. Crowson. Muzeum i Instytut Zoologii PAN, Warszawa, pp. 634-797.

Lawrence J.F. \& SpiLman T.J. 1991: Tenebrionidae (Tenebrionoidea) (including Alleculidae, Cossyphodidae, Lagriidae, Nilionidae, Rhysopaussidae, Tentyriidae). In Stehr F.W. (ed.): Immature Insects. Vol. 2. Kendall/Hunt Publishing Company, Dubuque, Iowa, pp. 520-528.

Nixon K.C. 1999: Winclada (BETA) ver. 1.00.08. K. C. Nixon, Ithaca, New York.

Nixon K.C. \& CARpenter J.M. 1993: On outgroups. Cladistics 9: 413-426.

Pollock D.A. 1991: Natural history, classification, reconstructed phylogeny, and geographical history of Pytho Latreille (Coleoptera: Heteromera: Pythidae). Mem. Entomol. Soc. Can. 154: 1-104.

Pollock D.A. 1995: Classification, reconstructed phylogeny and geographical history of genera of Pilipalpinae (Coleoptera: Tenebrionoidea: Pyrochroidae). Invertebr. Taxon. 9: 563-708.

Pollock D.A. \& Lawrence J.F. 1995: Review of Anaplopus Blackburn (Coleoptera: Pythidae), with comments on constituents and systematics of Pythidae. In Pakaluk J. \& Ślipiński S.A. (eds): Biology, Phylogeny, and Classification of Coleoptera: Papers Celebrating the $80^{\text {th }}$ Birthday of Roy A. Crowson. Muzeum i Instytut Zoologii PAN, Warszawa, pp. 449-472.

Pollock D.A., Ide S. \& Costa C. 2000: Review of the Neotropical genus Physiomorphus Pic (Coleoptera: Mycteridae: Lacconotinae), with description of the larvae of three species. J. Nat. Hist. 34: 2209-2239.

Schunger I., Beutel R.G. \& Britz R. 2003: Morphology of immature stages of Prostomis mandibularis (Coleoptera: Tenebrionoidea: Prostomidae). Eur. J. Entomol. 100: 357-370.

Selander R.B. 1991: Rhipiphoridae (Tenebrionoidea), Meloidae (Tenebrionoidea). In Stehr F.W. (ed.): Immature Insects. Vol. 2. Kendall/Hunt Publishing Company, Dubuque, Iowa, pp. 509-512, 530-534.

ŚLIPIŃSKI S.A. 1998: Revision and phylogeny of Protocucujidae (Coleoptera: Cucujoidea). Ann. Zool. 48: 275-298.

ŚLIPIŃSKI S.A. \& LAWRENCE J. F. 1999: Phylogeny and classification of Zopheridae sensu novo (Coleoptera: Tenebrionoidea) with a review of the genera Zopherinae (excluding Monommatini). Ann. Zool. 49: 1-53.

WatT J.C. 1967: The families Perimylopidae and Dacoceridae (Coleoptera, Heteromera). Proc. R. Entomol. Soc. Lond. (B) 36(7-8): 109-118.

Young D.K. 1991: Prostomidae (Tenebrionoidea), Synchroidae (Tenebrionoidea), Boridae (Tenebrionoidea), Pythidae (Tenebrionoidea), Pyrochroidae (Tenebrionoidea), Pedilidae (Tenebrionoidea), Othniidae (Tenebrionoidea), Salpingidae (Tenebrionoidea), Inopeplidae (Tenebrionoidea), Anthicidae (Tenebrionoidea), Euglenidae (Tenebrionoidea), Scraptidae (Tenebrionoidea). In Stehr F.W. (ed.): Immature Insects. Vol. 2. Kendall/Hunt Publishing Company, Dubuque, Iowa, pp. $515-518,537-456$

Received October 4, 2004; revised and accepted January 31, 2005 